\title{
Survival in Hostile Conditions: Pupylation and the Proteasome in Actinobacterial Stress Response Pathways
}

\author{
Tatjana von Rosen, Lena ML Keller and Eilika Weber-Ban*
}

Institute of Molecular Biology and Biophysics, ETH Zurich, Zurich, Switzerland

Bacteria employ a multitude of strategies to cope with the challenges they face in their natural surroundings, be it as pathogens, commensals or free-living species in rapidly changing environments like soil. Mycobacteria and other Actinobacteria acquired proteasomal genes and evolved a post-translational, ubiquitin-like modification pathway called pupylation to support their survival under rapidly changing conditions and under stress. The proteasomal $20 \mathrm{~S}$ core particle (20S CP) interacts with ring-shaped activators like the hexameric ATPase Mpa that recruits pupylated substrates. The

OPEN ACCESS

Edited by:

Kürşad Turgay,

Max-Planck-Gesellschaft (MPG),

Germany

Reviewed by:

Heran Darwin,

New York University, United States

David A Dougan,

La Trobe University, Australia

${ }^{*}$ Correspondence:

Eilika Weber-Ban

eilika@mol.biol.ethz.ch

Specialty section:

This article was submitted to

Protein Folding, Misfolding

and Degradation,

a section of the journal

Frontiers in Molecular Biosciences

Received: 25 March 2021

Accepted: 04 May 2021

Published: 07 June 2021

Citation:

von Rosen T, Keller $L M L$ and Weber-Ban E (2021) Survival in Hostile

Conditions: Pupylation and the Proteasome in Actinobacterial Stress

Response Pathways.

Front. Mol. Biosci. 8:685757.

doi: 10.3389/fmolb.2021.685757 proteasomal subunits, Mpa and pupylation enzymes are encoded in the so-called Pup-proteasome system (PPS) gene locus. Genes in this locus become vital for bacteria to survive during periods of stress. In the successful human pathogen Mycobacterium tuberculosis, the 20S CP is essential for survival in host macrophages. Other members of the PPS and proteasomal interactors are crucial for cellular homeostasis, for example during the DNA damage response, iron and copper regulation, and heat shock. The multiple pathways that the proteasome is involved in during different stress responses suggest that the PPS plays a vital role in bacterial protein quality control and adaptation to diverse challenging environments.

Keywords: pupylation, bacterial proteasome, degradation, DNA Damage, metal homeostasis, oxidative stress, mycobacteria, Mycobacterium tuberculosis

\section{INTRODUCTION}

Bacteria cultured in the laboratory are generally grown in pure, liquid culture under optimal conditions. They are provided with a balanced mix of nutrients including carbon and nitrogen sources along with minerals and trace elements, shaken for good aeration and kept at their favorite temperature. However, in the real world, bacterial life is frequently harsh and far from ideal (Haruta and Kanno, 2015). This certainly applies to Actinobacteria that constitute one of the largest and most diverse phyla in the bacterial kingdom (Barka et al., 2016). Its members exhibit a variety of lifestyles: as soil inhabitants living in rapidly changing environments in competition or symbiosis with other microorganisms, as pathogens under nutrient limitation and subject to host defense mechanisms or as plant and gastrointestinal commensals. As a consequence of their exposure to changing nutritional conditions and a multitude of stresses, Actinobacteria evolved a particularly high adaptive ability allowing them to persist in their often-hostile environments (Figure 1).

Adaptation ultimately requires that the proteome present at a given moment under a defined set of conditions can be reshaped efficiently to reflect the new needs of the organism. On the one hand 
A

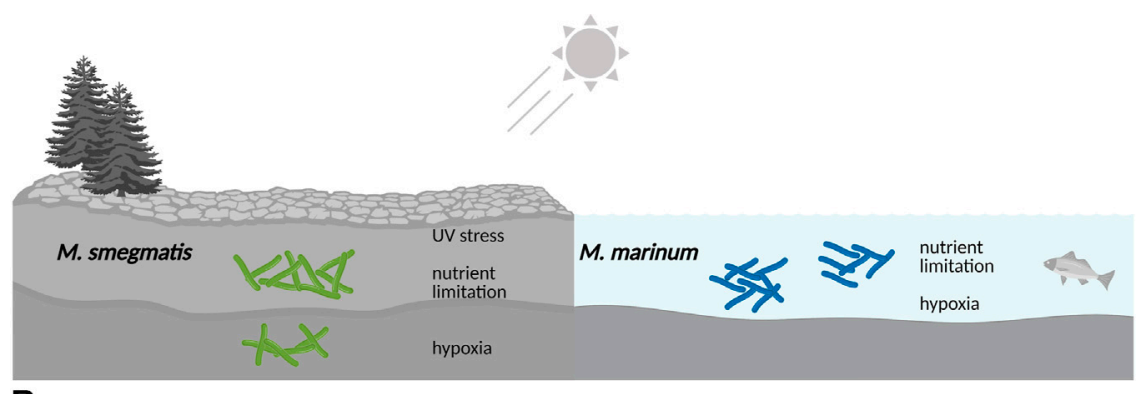

B
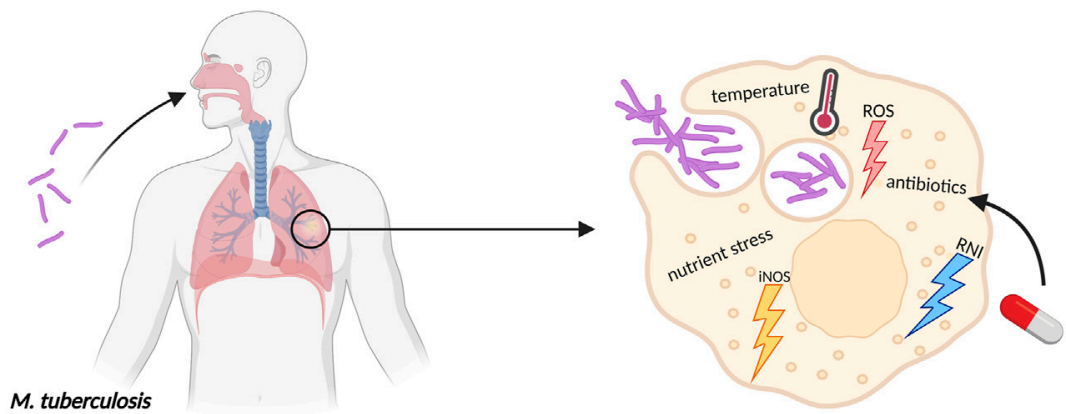

FIGURE 1 | Mycobacteria frequently encounter adverse conditions in their natural surroundings, requiring coordinated stress responses. (A) Free living mycobacteria, like the soil-dwelling M. smegmatis or the ocean bacterium M. marinum, are exposed to UV radiation, experience sudden changes in temperature, have to adjust to varying oxygen levels, and need to survive periods of limitation in essential nutrients like carbon, nitrogen and iron minerals. (B) Pathogenic mycobacteria like $M$. tuberculosis are exposed to hostile environments when growing inside host macrophages, where they also face sudden changes in nutrient availability, pH and temperature. The defensive mechanisms of macrophages include the production of reactive oxygen species (ROS), nitric oxide synthase in its inducible isoform (iNOS), and reactive nitrogen intermediates (RNI). Furthermore, exposure to antibiotics during drug treatment of $M$. tuberculosis infections also elicits stress responses in an attempt to evade killing and develop resistance.

this is achieved through changes in gene expression involving regulation on the transcriptional and translational levels (Guo and Gross, 2014; Martin and Liras, 2020). On the other hand, an efficient and robust proteomic response to stress and changing nutritional states also requires controlled protein turnover (Gerth et al., 2008; Michalik et al., 2012; Guo and Gross, 2014). The balanced production and breakdown of proteins referred to collectively as protein homeostasis, is also required under normal conditions and presents a fundamental activity of all living cells. The degradation branch of protein homeostasis permits a rapid adaptive response that is independent of and complements the changes in transcription and translation. It is also independent of bacterial growth and therefore particularly important for bacteria that are not growing actively (Trotschel et al., 2013), such as pathogenic bacteria residing in the host in dormant or extremely slow-growing states or bacteria under nutrient limiting conditions.

Mycobacteria are amongst the most notorious members of Actinobacteria, owed largely to Mycobacterium tuberculosis (Mtb), one of the most successful human pathogens of all time, currently responsible for 1.5 million deaths and more than 10 million infections every year worldwide (WHO, 2020).
As an intracellular pathogen, Mtb has to survive behind enemy lines, residing inside host macrophages, where it needs to resist the defensive onslaught of oxidative and nitrosative stress and adapt to nutritional deficiencies (Awuh and Flo, 2017). Mtb can persist in the host in a slow-growing/dormant state for decades, from which it can resume growth and progress to clinical disease (Jayachandran et al., 2012). The identification of pathways supporting persistence in the host has long been a focus of research toward combatting Mtb. One such pathway is centered around a bacterial proteasome gene locus characteristic to the phylum of Actinobacteria (Darwin et al., 2003; Gandotra et al., 2007). The existence of proteasomes in this phylum has been known since the early 1990's, when a proteasomal particle was first observed in nitrogen-fixing bacterium Frankia (Benoist et al., 1992). However, unlike eukaryotes, bacteria generally do not encode proteasomal subunits, but have their own version of compartmentalizing proteases (Clp proteases, HslUV and $\mathrm{FtsH})$ that are responsible for regulated protein turnover and protein quality control (Knipfer et al., 1999; Laederach et al., 2014). The proteasome is thus an unusual occurrence in bacteria restricted largely to the phylum Actinobacteria, where it is found in addition to other typical bacterial degradation 


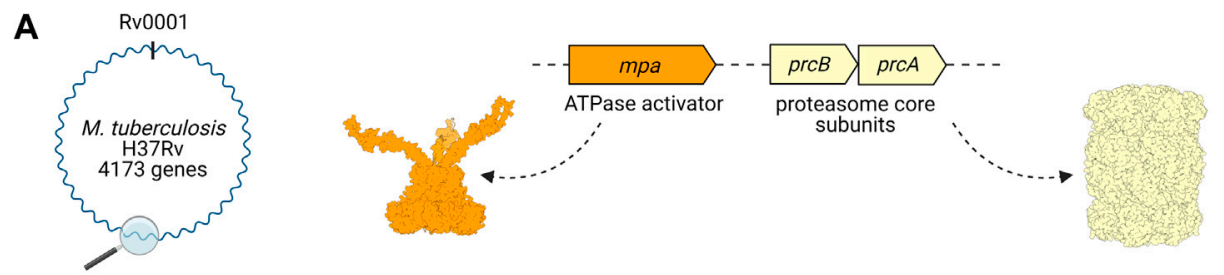

PPS: Rv2109c - Rv2115c ; Rv2095c - Rv2097c

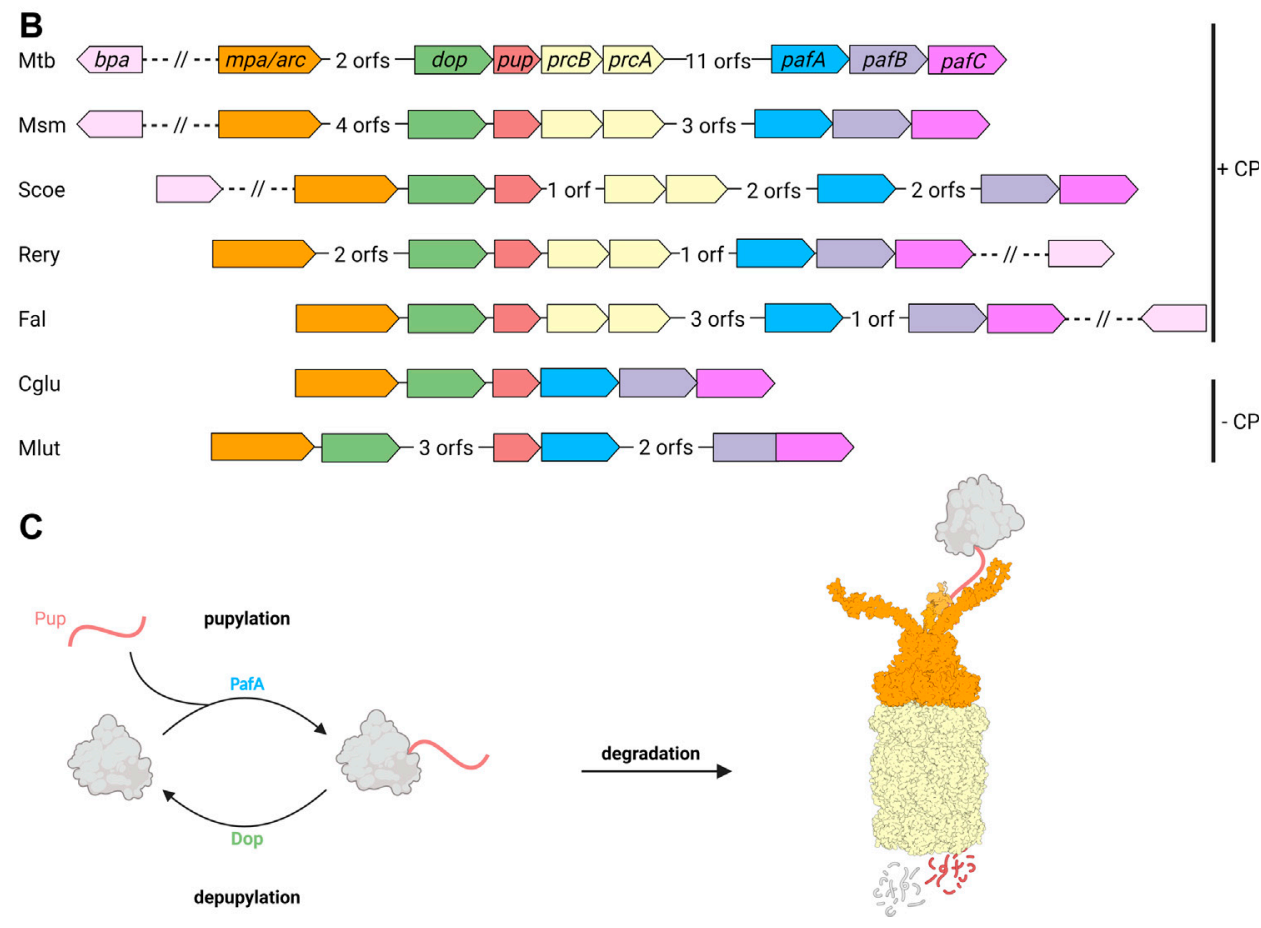

FIGURE 2 | Genes involved in pupylation and Pup-dependent proteasomal degradation are organized in the Pup-proteasome gene locus in Actinobacteria. (A) Members of the Pup-proteasome system (PPS) are encoded in close proximity to one another in the PPS gene locus, ranging from Rv2109c to Rv 2097c in Mtb. The genes coding for the hexameric ATPase Mpa (Rv2115c, orange) and proteasomal $\alpha$ and $\beta$ subunits PrcA and PrcB (Rv2109 and Rv2110c, beige), were most likely acquired by horizontal gene transfer. (B) In addition to Mpa/ARC and the $20 S$ proteasomal subunits, the PPS gene locus also encodes the ubiquitin-like protein Pup (Rv2111c, red), the Pup-ligase PafA (Rv 2097c, blue), and the depupylase Dop (Rv2112c, green). The transcriptional regulator PafBC (Rv 2096c and Rv 2095c, purple), is found in close proximity to PafA and has been shown to regulate the major DNA damage response in mycobacteria, to which the PPS is tightly linked. The alternative ring shaped ATP- and pupylation-independent activator Bpa (Rv3780, light pink) is not found in the Pup-Proteasome gene locus, but strictly co-occurs with the proteasomal subunit genes across Actinobacteria. A subgroup of Actinobacteria is missing the proteasomal subunit genes in their PPS locus, likely by secondary loss during evolution. Mtb, Mycobacterium tuberculosis; Msm, Mycobacterium smegmatis; Scoe, Streptomyces coelicolor; Rery, Rhodococcus erythropolis; Fal, Frankia alni; Cglu, Corynebacterium glutamicum; Mlut, Micrococcus luteus. (C) Pupylation involves the post-translational modification of target proteins (grey) with Pup (red), and is catalyzed by the Pup ligase PafA. Pupylated proteins are either depupylated by the deamidase Dop or recruited to the Mpa-20S proteasome complex for unfolding and degradation.

complexes (Laederach et al., 2014). Originally adopted by horizontal gene transfer, the proteasome gene locus has evolved to support the organisms during stress, for example in Mtb contributing to its persistence inside host macrophages (Darwin et al., 2003; Gandotra et al., 2007).

Around the 20S CP and its regulatory ATPase partner Mpa, both homologous to eukaryotic $26 \mathrm{~S}$ proteasomes, a novel substrate recruitment pathway has evolved in Actinobacteria that shows functional parallels to ubiquitination, but is of distinct, exclusively bacterial origin (Pearce et al., 2008; Burns et al., 2009; Sutter et al., 2009). Through this pathway termed pupylation, substrate proteins are post-translationally modified with the small, intrinsically disordered protein Pup (prokaryotic ubiquitin-like protein) (Pearce et al., 2006; Burns et al., 2009). Pupylation can be reversed and both the ligase and depupylase enzymes are encoded in the gene locus where the genes for the proteasomal degradation machinery and the modifier Pup reside (Burns et al., 2010; Imkamp et al., 2010). This locus, referred to as the Pup proteasome system (PPS) gene locus, is present in all Actinobacteria, however, a subset of organisms in this phylum has lost the proteasomal subunits despite maintaining pupylation (Figure 2). 


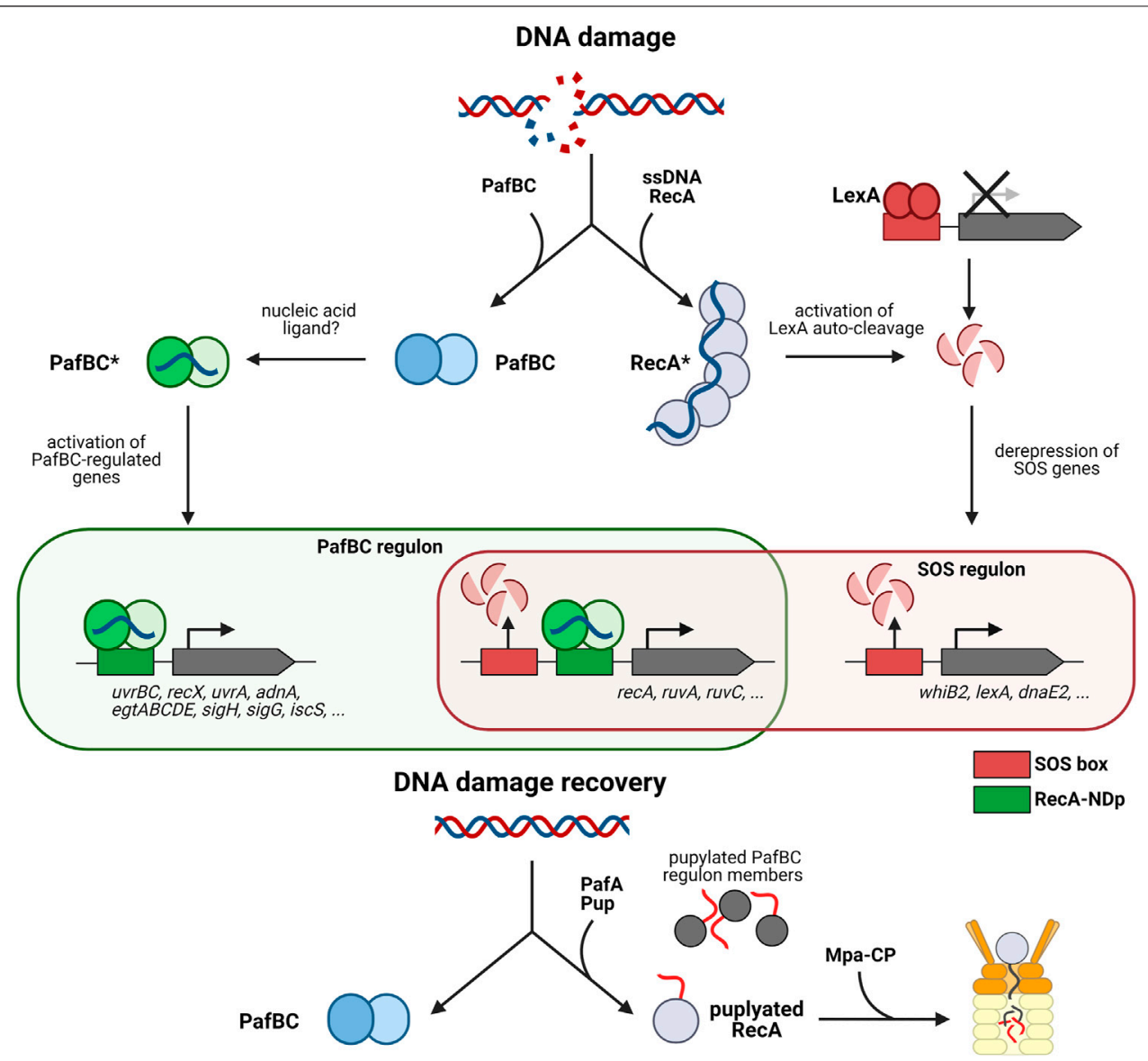

FIGURE 3|The pupylation locus in involved in the mycobacterial DNA damage response. The mycobacterial DNA damage response is mediated by two pathways, the SOS response mediated by repressor LexA and the response mediated by activator PafBC. The canonical SOS response pathway is illustrated on the right (LexA RecA-dependent pathway). Upon DNA damage RecA forms filaments on ssDNA, which stimulates auto-cleavage of the repressor LexA. LexA dissociates from the SOS box which in turn, upregulates transcription of DNA damage response genes such as recA. The left side shows the PafBC-dependent DNA damage response pathway. Upon binding of a response-producing ligand (hypothesized to be a nucleic acid) PafBC is activated and binds to the RecA-NDp promoter, activating the transcription of many genes involved in DNA repair and oxidative stress response. Upon return to normal conditions, RecA along with several other PafBC regulon members (EgtD, TopoN, IscS, RuvA, etc.) are pupylated and removed by the Pup-proteasome system to recover fully from DNA damage. Interestingly, some genes such as recA, uvrA, and uvrC are regulated by the PafBC regulon as well as the SOS regulon.

In this review article, we highlight the roles that pupylation and the Pup proteasome gene locus play in the survival strategy of mycobacteria and other Actinobacteria under stress.

\section{PUPYLATION-DEPENDENT PROTEASOMAL DEGRADATION PLAYS A ROLE IN ACTINOBACTERIAL STRESS RESPONSES}

The actinobacterial $20 \mathrm{~S}$ proteasome, like its eukaryotic relative, forms the core of the fully assembled protease complex (Nagy et al., 1997; Wolf et al., 1998; Lin et al., 2006). It is built from four stacked homo-heptameric rings, the inner two $\beta$-rings carrying the proteolytic active sites, framed by the two $\alpha$-rings that shape the entrance pores into the degradation chamber. In order to degrade substrate proteins post-translationally modified with
Pup, the a-rings of the $20 \mathrm{~S}$ particle associate with a likewise ring-shaped hexameric ATPase of the AAA family, called Mpa (mycobacterial proteasome ATPase) in mycobacteria or ARC (ATPase forming ring-shaped complexes) in other Actinobacteria (Wolf et al., 1998; Darwin et al., 2005; Striebel et al., 2010). Mpa employs a C-terminal proteasome interaction motif (GQYL) that retains the same penultimate aromatic residue as the HbYX motif of eukaryotic proteasome interactors (Darwin et al., 2005; Pearce et al., 2006; Smith et al., 2007; Rabl et al., 2008; Striebel et al., 2010). Both motifs insert into deep binding pockets located between the $\alpha$-subunits of the 20S CP, featuring a binding site for the aromatic residue and a lysine residue to interact with the C-terminal carboxylate.

The covalent modification of proteins at lysine residues with Pup is catalyzed by the ligase PafA (proteasome accessory factor A) in a two-step mechanism (Guth et al., 2011). This involves the formation of an isopeptide bond between the C-terminal glutamate side chain carboxylate of Pup and the $\varepsilon$-amino 
TABLE 1 | Overview of the involvement of the 20 S proteasome in select stress conditions in various Actinobacteria described in this review.

\begin{tabular}{|c|c|c|c|c|}
\hline Stress Condition & Involvement of proteasome or pupylation & Substrates & Organism & References \\
\hline Oxidative stress & Regulation of differentiation and resistance & Unknown & $\begin{array}{l}\text { M. tuberculosis } \\
\text { S. coelicolor }\end{array}$ & $\begin{array}{l}\text { Darwin et al. (2003); De Mot et al. } \\
\text { (2007); Boubakri et al. (2015); Compton } \\
\text { et al. (2015) }\end{array}$ \\
\hline $\begin{array}{l}\text { Reactive nitrogen } \\
\text { intermediates (NO) }\end{array}$ & $\begin{array}{l}\text { Removal of cytokinin producing enzyme } \\
\text { (cytokinin breakdown products sensitize Mtb } \\
\text { to } \mathrm{NO} \text { ) }\end{array}$ & Cytokinin synthesis enzyme Log & M. tuberculosis & $\begin{array}{l}\text { Darwin et al. (2003); Pearce et al. } \\
\text { (2006); Samanovic et al. (2015); } \\
\text { Samanovic et al. (2018) }\end{array}$ \\
\hline Nitrogen limitation & $\begin{array}{l}\text { Recycling of amino acids for biogenesis; } \\
\text { folding of proteins involved in nitrogen } \\
\text { assimilation }\end{array}$ & $\begin{array}{l}\text { Multiple proteins involved in nitrogen } \\
\text { metabolism and assimilation (ex. } \\
\text { GlnA, HrcA) }\end{array}$ & $\begin{array}{l}\text { M. smegmatis } \\
\text { M. tuberculosis }\end{array}$ & $\begin{array}{l}\text { Becker et al. (2019); Fascellaro et al. } \\
\text { (2016) }\end{array}$ \\
\hline DNA damage & $\begin{array}{l}\text { Transcription activation of DNA repair genes } \\
\text { and pupylation of DNA repair proteins during } \\
\text { recovery }\end{array}$ & $\begin{array}{l}\text { Broad range of DNA repair proteins } \\
\text { (ex. RecA) }\end{array}$ & M. smegmatis & $\begin{array}{l}\text { Olivencia et al. (2017); Müller et al. } \\
\text { (2018); Müller et al. (2019) }\end{array}$ \\
\hline Iron limitation & Release of iron storage & Ftn & C. glutamicum & Küberl et al. (2016); Küberl et al. (2014) \\
\hline Copper homeostasis & $\begin{array}{l}\text { Involvement in regulation of RicR regulon (ex. } \\
\text { MymT and } \mathrm{MmcO} \text { ) }\end{array}$ & Unknown & M. tuberculosis & Festa et al. (2011); Shi et al. (2014) \\
\hline Heat shock & $\begin{array}{l}\text { ATP- and pupylation-independent degradation } \\
\text { of HspR to allow chaperone expression (e.g. } \\
\text { DnaK and ClpB) }\end{array}$ & HspR & M. tuberculosis & $\begin{array}{l}\text { Jastrab et al. (2015); Jastrab et al. } \\
\text { (2017) }\end{array}$ \\
\hline Carbon starvation & Unknown & Unknown & M. smegmatis & Ziemski et al. (2018) \\
\hline
\end{tabular}

group of the target lysine by nucleophilic substitution. PafA has been suggested to have evolved from an ancient glutamyl-amine ligase enzyme (glutamine synthetase or $\gamma$-glutamyl cysteine ligase) based on its sequence and structural homology to this class of enzymes (Iyer et al., 2008; Sutter et al., 2009; Özcelik et al., 2012; Hecht et al., 2021). The structurally homologous enzyme Dop (deamidase of Pup), also encoded in the PPS gene locus, catalyzes the opposing activity by cleaving the isopeptide bond between Pup and substrates (Burns et al., 2010; Cerda-Maira et al., 2010; Imkamp et al., 2010; Bolten et al., 2017). Mycobacteria and a number of other Actinobacteria encode Pup with a C-terminal glutamine instead of glutamate, necessitating deamidation of the glutamine side chain prior to ligation. Interestingly, deamidation, which is chemically equivalent to depupylation, is also carried out by Dop (Striebel et al., 2009).

The modifier Pup despite its name is unrelated in structure and sequence to ubiquitin. Pup is an intrinsically disordered protein of 64 residues with a molecular mass under $7 \mathrm{kDa}$ in $\mathrm{Mtb}$ (Chen et al., 2009; Liao et al., 2009; Sutter et al., 2009). The disordered ensemble state typical for intrinsically disordered proteins is present in both free Pup and when it is covalently attached to protein substrates (Barandun et al., 2017). However, it undergoes disorder-to-order transitions upon binding to the pupylation enzymes (ligase and depupylase) (Barandun et al., 2013) or to the proteasomal regulator Mpa (Wang et al., 2010). Interestingly, it adopts different conformations depending on the binding partner (Delley et al., 2017). Interaction with the ligase and depupylase results in the formation of two orthogonal, shorter helices that ensure a snug fit into the Pup binding groove of the enzymes (Barandun et al., 2013). As a recognition tag for proteasomal degradation, Pup binds to the $\mathrm{N}$-terminal coiled-coil domains at the Mpa ring surface, forming a single longer helix that joins the coiled-coil (Sutter et al., 2009; Wang et al., 2010). Once bound, Mpa/ARC unfolds the pupylated substrate and translocates it into the $20 \mathrm{~S}$ proteasome degradation chamber in an ATP-dependent manner (Striebel et al., 2010).

In addition to the genes required for pupylation and proteasomal degradation, including $p u p, p a f A, d o p, a r c / m p a$, and the proteasomal subunits $\operatorname{prc} A / B$, the PPS gene locus also encodes the transcriptional regulator PafBC (Olivencia et al., 2017) (Figure 2B). In mycobacteria, PafBC (proteasome accessory factor B and C) is encoded in the same operon together with the Pup ligase PafA, giving rise to the name (Festa et al., 2007). Although this is not the case in all Actinobacteria, the $p a f B C$ genes are nevertheless tightly associated with the PPS locus and are found in close proximity downstream of the pafA gene. PafBC is important for the mycobacterial DNA damage response and ties the PPS locus to stress conditions with DNA damaging potential like oxidative stress, UV exposure or DNA damaging natural compounds produced by other microorganisms (Müller et al., 2018).

Besides Mpa/ARC, the 20S bacterial proteasome can interact with alternative ring-shaped activators not encoded in the Pup proteasome gene locus, including the ATPase Cpa (Cdc48-like protein of Actinobacteria) and the ATP-independent Bpa (bacterial proteasome activator, also referred to as PafE) (Delley et al., 2014; Jastrab et al., 2015; Ziemski et al., 2018). Although recruitment of substrate proteins to these alternative proteasomal complexes does not involve pupylation, they also play a role in adaptation to stressful conditions and will be discussed later in this review.

\section{Mycobacterial Stress Responses to Nitrogen Starvation or Reactive Nitrogen Intermediates Involve Pupylation and Proteasomal Degradation}

Nitrogen plays an essential role for all living organisms, since it is a major constituent of the biological molecules making up a cell's 
proteome, its hereditary material in the form of DNA and RNA, signaling molecules, cell wall constituents, cofactors and many other fundamentally important biomolecules. Bacteria generally use it in its reduced form as ammonium for incorporation into amino acids, thereby providing the building blocks for protein biogenesis. This involves uptake via ammonium transporters and assimilation into glutamine or glutamate via glutamine synthetase and glutamate synthase or glutamate dehydrogenase (Herrero et al., 2019). Of course, bacteria can also directly take up glutamate and glutamine or other amino acids like arginine and aspartate that can be further metabolized. In fact, Mtb is able to take up all 20 proteinogenic amino acids from the environment and prefers amino acids over ammonia as nitrogen source (Agapova et al., 2019). Furthermore, when ammonium is scarce, Actinobacteria, like most bacteria can take up nitrogen from the environment in the form of nitrate and metabolize it to ammonium. In this pathway, nitrate is first metabolized to nitrite via the nitrate reductase NarGHIJ complex, and the nitrite reductase complex NirBD then further reduces nitrite to ammonium that can be assimilated into amino acids (Malm et al., 2009). These enzymes contain iron-sulfur clusters and the reductions involve radical chemistry.

Regulatory mechanisms of nitrogen metabolism are geared toward ensuring sufficient nitrogen supply, and they generate a swift response to changed nutritional conditions like different nitrogen sources, nitrogen limitation or starvation. At the same time, the organism must avoid accumulation of toxic nitrogen compounds like nitrite that have the ability to produce radicals and damage DNA, lipids and proteins. Furthermore, pathogenic organisms have to contend with reactive nitrogen species generated by host defense mechanisms. Consequently, Actinobacteria can experience stress connected to nitrogen metabolism in two ways, as starvation stress or as toxic stress. The PPS appears to play a role in both types of nitrogen stress.

$\mathrm{Mtb}$ is an intracellular pathogen that makes a home of the very cells that phagocytose it (Huang et al., 2019). Inside the host macrophage, Mtb prevents phagosome maturation and ultimately persists in this organelle. During establishment of persistence, the interplay of host immune defense mechanisms and Mtb evasive counteraction results in formation of a granuloma, a walled-off, fibrous structure with a macrophagerich center, where $\mathrm{Mtb}$ reside and slowly proliferate (Queval et al., 2017; BoseDasgupta and Pieters, 2018). An important factor in controlling Mtb infection is the production of nitric oxide by activated host macrophages through the activity of inducible nitric oxide synthase (NOS2) (MacMicking et al., 1997) as well as reactive oxygen species (ROS) via the superoxide generating enzyme NOX2 (Fang, 2004). Inside the phagosome, this leads to the generation of nitrite that can be protonated and produce radical forms of nitric oxide and other lethal nitrogen intermediates (Stuehr and Nathan, 1989). A transposon mutagenesis screen aimed at identifying genes that render Mtb more resistant to reactive nitrogen intermediates uncovered a role of the proteasome gene locus in survival of nitrosative stress (Darwin et al., 2003). Disruption of both mpa and pafA resulted in increased sensitivity of Mtb to acidified nitrite and cultures treated with proteasome inhibitor also showed less resistance under these conditions. Furthermore, the deletion strains were attenuated in a mouse infection model, demonstrating that proteasomal degradation and pupylation support Mtb survival in the host. It was hypothesized that the proteasomal degradation pathway might be involved in removal of proteins damaged by RNI and ROS. The chemical effects of both RNI and ROS and the nonspecific damage they cause to proteins, lipids and DNA will be discussed in more detail in a later section of this review. However, the connection between the PPS locus and NO stress turned out to be more complex, affecting several specific pathways, which will be the focus in this section of the review.

One mechanism was identified for the PPS locus in Mtb through a suppressor mutagenesis screen of NO sensitivity (Samanovic et al., 2015). The screen showed that disruption of a gene with homology to a plant enzyme involved in cytokinin biosynthesis called "lonely guy (LOG)" could reverse the NOhypersensitive phenotype of the mpa deletion strain, suggesting that increased cytokinin production during infection was responsible for the observed phenotype. Plant LOG enzymes possess cytokinin-specific phosphoribohydrolase activity, cleaving the inactive cytokinin nucleotides to release the active free-base cytokinins (Kurakawa et al., 2007). Indeed, Mtb Log ( $\mathrm{Rv} 1205)$ produces cytokinins in Mtb and is a pupylation target. It accumulates in the mpa deletion strain as well as in a mutant strain where the target lysine is changed to alanine, indicating that Log is degraded by the Mpa-proteasome in a pupylationdependent manner (Samanovic et al., 2015) (Table 1).

Cytokinins are adenine derivatives with substitutions at the amino group at $\mathrm{C} 6$ of the purine ring. In $\mathrm{Mtb}$, isoprenoid cytokinins like N6-( $\Delta 2$-isopentenyl)adenine (iP) or 2methylthio-iP are the most abundant. While it is wellestablished that in plants cytokinins act as hormones influencing cell growth and differentiation (Mok and Mok, 2001), their role in bacteria and specifically in Mtb is less well understood. In a follow-up study to the suppressor screen, the authors observed cytokinin-induced upregulation of a protein of unknown function (Rv0077c) that resulted in loss of acid-fast staining of $\mathrm{Mtb}$, hinting at a possible remodeling of components in the cell envelope (Samanovic et al., 2018). They could show that Rv0077c is repressed by neighboring TetR-like repressor Rv0078 in absence of cytokinins. However, in the mouse model of tuberculosis, constitutive expression of Rv0077c by disruption of the repressor gene did not affect virulence, leaving it unclear in which phase of infection and in what way the bacterium benefits from the upregulation. Interestingly, Rv0077c was reported as a putative pupylation substrate in a proteomic study previously, suggesting that the PPS might be involved in its removal after upregulation (Festa et al., 2010).

Regardless of their biological role in Mtb, the fact that production of cytokinins can render the bacterium sensitive to NO appears to be due to breakdown of cytokinins into aldehydes, which are rendered toxic in additional presence of $\mathrm{NO}$ (Samanovic et al., 2015). Pup-dependent degradation of Log prevents the cytokinin levels from overshooting and thereby supports survival during infection. This finding shows that the degradation of a specific pupylation substrate, in this case Log, can contribute significantly to the NO-sensitive phenotype of 
Mtb. Homologs of Log are also found in M. smegmatis (Msm) (MSMEG_5087), M. bovis (Mb1237), and M. marinum (MMAR_4233), suggesting that other mycobacteria also might produce cytokinins under certain conditions.

In eukaryotes, it is known that the proteasome is essential to recycle amino acids and hence contributes to nutrient homeostasis in the cell (Vabulas and Hartl, 2005; Suraweera et al., 2012). A similar role was proposed for the PPS in Msm under nitrogen starvation. An Msm strain deficient in pup and the proteasomal subunit genes exhibited a significantly more severe growth defect upon nitrogen limitation than the parent strain (Elharar et al., 2014). Interestingly, during the onset of nitrogen limitation $(24 \mathrm{~h})$ an increase in the levels of pupylated proteins was observed, but they were almost completely degraded a week into the starvation stress. Furthermore, probing of PPS member levels indicated that nitrogen starvation in Msm induces oscillations in their abundance for the duration of the starvation stress (Elharar et al., 2014), an expression phenotype that could not be observed under similar conditions for Mtb (Becker et al., 2019). The authors hypothesize that during nitrogen starvation the PPS takes the role of an amino acid recycling pathway to provide the bacterium with the required protein building blocks in times when amino acids cannot be obtained by de novo synthesis or from the environment.

Another study proposed that the PPS might also play a more specific role during nitrogen starvation in Msm by adjusting the levels of enzymes involved in nitrogen assimilation pathways (Fascellaro et al., 2016). Msm encodes a particularly high number of nitrogen related genes involved in nitrogen uptake, assimilation and regulation (Amon et al., 2009). The transcriptional regulator $\mathrm{GlnR}$ is the global nitrogen response regulator in Msm, controlling primary nitrogen metabolism and the switch to nitrate or urea as alternative nitrogen sources (Jenkins et al., 2013). Proteome analysis of an Msm pup deletion strain under nitrogen starvation revealed that levels of 17 proteins of nitrogen metabolism were altered compared to the parent strain under the same starvation stress, 9 of them members of the GlnR regulon. Interestingly, the nitrite reductase, regulator $\mathrm{GlnR}$, as well as GlnR-regulated proteins (e.g. glutamine synthetase GlnA1) were less abundant in the pup deletion strain, thereby precluding straightforward Pup-mediated degradation. Furthermore, for some of them, lower mRNA levels were observed when pupylation was absent. Irrespective of the exact mechanism of regulation, these proteins play an important role for nitrogen assimilation when nutrients are limited and the PPS is involved in their regulation.

The nature of this involvement was elucidated for nitrate assimilation of Mtb (Becker et al., 2019). It was observed that Mtb strains deficient in either the $m p a$, pafA or $\operatorname{prcBA}$ genes could no longer grow on nitrate as a nitrogen source and secreted large amounts of nitrite, suggesting that the nitrate assimilation pathway was impaired at the level of the nitrite reductase complex NirBD, leading to accumulation of toxic levels of nitrite. A suppressor screen aimed at restoring the ability of the mpa mutant strain to assimilate nitrate, identified HrcA as a suppressor gene (Becker et al., 2019). HrcA is a transcriptional regulator that represses the chaperonin system genes groES
(Rv3418c), groEL1 (Rv3417c) and groEL2 (Rv0440), and the gene Rv0991c (Stewart et al., 2002b). The authors could show that HrcA is a pupylation target in vitro (Becker et al., 2019). The fact that groEL2 is suppressed in the mpa mutant strain is thus a direct consequence of impaired proteasomal degradation of HrcA. Client proteins of GroELS chaperonins require its function in order to gain their natively folded, active state (Horwich et al., 1993; Kong et al., 1993; Kumar et al., 2015; Horwich and Fenton, 2020). The strongly diminished nitrite reduction activity in the $m p a$ mutant strain suggests that NirBD is functionally impaired due to deregulated GroELS levels. The screen also identified mutations in an essential gene that encodes the enzyme catalyzing the committed step in NAD biosynthesis (nadD). These turned out to be gain-offunction mutations boosting NAD levels and thereby supporting NirBD activity, which requires the presence of adequate levels of $\mathrm{NAD}^{+} / \mathrm{NADH}$.

These findings illustrate that the PPS gene locus also influences nitrogen metabolic networks by indirectly affecting transcriptional regulation of a quality control pathway. The uncovered link likely also contributes to the observation that silencing of the $\operatorname{prcBA}$ genes in Mtb leads to lowered resistance against sodium nitrite and lowered persistence in mice (Gandotra et al., 2007). The effect of the PPS on nitrogen metabolism and resistance to nitric oxide stress is multifaceted and complex, highlighting the prominent role that pupylation and proteasomal degradation plays in nitrogen homeostasis.

\section{The Pup-Proteasome Gene Locus and the DNA Damage Response}

Stable transmission of genetic information from one generation to the next is crucial for all living organisms. Although some level of mutagenesis provides the genetic diversity that allows bacteria to evolve, global DNA damage that would reduce their fitness and threaten survival must be dealt with swiftly. Mycobacteria, for example, are frequently exposed to conditions that can damage their genetic material, like macrophagegenerated reactive oxygen species and reactive nitrogen intermediates experienced by pathogenic members inside the host (Weiss and Schaible, 2015), and UV exposure, metabolic endogenous oxidative or nitrosative stress or DNA damaging chemicals produced by other microorganisms for free-living mycobacteria.

The first indication that the PPS gene locus plays a role in the mycobacterial DNA damage response came from the observation that the levels of SOS response regulator, recombinase $A(\operatorname{Rec} A)$, are significantly reduced in an $\mathrm{Msm}$ pafBC deletion strain (Olivencia et al., 2017) (Table 1). Although in mycobacteria, the homologous $\mathrm{PafB}$ and $\mathrm{PafC}$ proteins are encoded in an operon together with Pup ligase PafA (Festa et al., 2007; Olivencia et al., 2017), it was shown early on, that they are not required for degradation of proteasomal substrates (Festa et al., 2007). Their predicted $\mathrm{N}$-terminal winged helix-turn-helix domains suggested that they might be involved in transcriptional regulation. Indeed, it was shown that $\operatorname{rec} A$ transcript levels are decreased in a 
$\triangle p a f B C$ strain compared to wild type and can be restored by complementation with pafBC (Olivencia et al., 2017).

Since its discovery about 40 years ago, the LexA/RecAmediated SOS response had been considered the main regulation pathway of the bacterial DNA damage response (Radman, 1975; Little and Mount, 1982; Shinagawa, 1996). Under conditions where the bacteria do not experience DNA damage stress, DNA repair genes preceded by the so-called SOS box sequence are repressed by transcriptional repressor LexA. Single-stranded DNA (ssDNA) fragments occurring as a consequence of DNA damage, trigger derepression of these genes by a mechanism involving RecA, where RecA and ssDNA form a nucleoprotein filament that binds to LexA, triggering its autocatalytic cleavage and dissociation from the SOS box (Galletto et al., 2006; Giese et al., 2008; Butala et al., 2011). As it is also an important enzyme in the process of homologous recombination, RecA plays a dual role during DNA damage stress, namely as stress sensor and as a repair enzyme.

Mycobacteria also possess this canonical repression/release mechanism via LexA and RecA, and by affecting RecA levels PafBC impacts the SOS response (Figure 3). In Mtb, roughly 25 genes were reported to be under LexA control, amongst them also recA itself (Smollett et al., 2012). However, it was realized early on that the majority of inducible DNA repair genes in Mtb can still be induced in the absence of the $\operatorname{rec} A$ gene, suggesting that a LexA/RecA-independent pathway must exist (Davis et al., 2002; Rand et al., 2003). In fact, based on the available transcriptomic data, it was even possible to deduce a consensus motif for this hypothetical additional pathway, aptly named RecA-NDp (RecAindependent promoter) based on the fact it is not regulated by the canonical pathway (Gamulin et al., 2004). Furthermore, the RecA-NDp promoter is not restricted to mycobacteria but extends to other Actinobacteria. The nature of regulation of this pathway and the identity of the regulator, however, remained unknown.

It was only recently that a fuller picture began to emerge. A combination of transcriptomics and genome-wide PafBC binding site analysis in Msm revealed that PafBC acts as a global transcriptional activator, controlling a regulon of more than 150 genes in response to the DNA damaging agent mitomycin C (Müller et al., 2018) (Figure 3). Members of the regulon include many proteins involved in DNA replication, recombination and repair, like for example the UvrABC nucleotide excision repair complex, the two main end resectioning complexes RecBCD and $\mathrm{Adn} A \mathrm{~B}$, important for homologous recombination, along with strand exchange mediating RecA and holiday junction binding protein RuvA and resolvase RuvC. Sigma factor $\mathrm{H}$ shown to be activated in Mtb upon heat stress and oxidative stress (Sharp et al., 2016), is also upregulated by PafBC (Müller et al., 2018). Likewise the gene cluster for the biosynthesis of the protective, redox-active compound ergothioneine is present in the regulon. This suggests that PafBC is also important for the oxidative stress response discussed in the next section of this review.

Interestingly, the consensus sequence motif identified for PafBC binding closely resembles the RecA-NDp motif. These results not only established $\mathrm{PafBC}$ as the elusive regulator of the
LexA/RecA-independent DNA damage response pathway, but furthermore demonstrated that transcriptional activation in addition to repression-release is involved in the transcriptional response to DNA stress (Müller et al., 2018). Among the members in the regulon are several genes that feature both the RecA-NDp as well as the SOS box in their upstream regions and are thus regulated by both the PafBC-dependent activating branch and the LexA/RecA-repression-release branch of the DNA damage response. RecA itself is regulated by both pathways, indicating that PafBC also indirectly influences the SOS response and that there exists tight cooperation between the two pathways (Figure 3).

The study also provided a functional link to the PPS, explaining the association of PafBC with that gene locus. Determination of the pupylated proteome present in $\mathrm{Msm}$ exposed to mitomycin C-induced DNA stress identified 26 PafBC regulon member proteins as pupylation targets, including RecA (Müller et al., 2018). Analysis of the RecA protein levels during mitomycin $\mathrm{C}$ exposure and in the recovery phase after removal of the DNA damaging reagent, showed that only wild type Msm but not Msm strains deficient in pupylation or proteasomal degradation were able to return RecA to pre-stress levels (Müller et al., 2018). This demonstrates that the PPS is required to ensure a temporally controlled, transient DNA stress response.

Although PafBC activates its regulon members specifically under DNA stress, the mRNA and protein levels of PafBC remain unchanged upon DNA stress exposure, indicating that a response-producing ligand is most likely involved (Olivencia et al., 2017; Müller et al., 2018). Based on its primary sequence, PafBC was classified with a family of bacterial regulators containing a so-called WYL domain, a domain of unknown function named for a conserved, consecutive Trp-TyrLeu sequence motif. Determination of the crystal structure of a naturally fused PafBC ortholog from Arthrobacter aurescens revealed that the $\mathrm{N}$-terminal winged helix-turn-helix domain is followed by a domain containing the conserved WYL motif and featuring an Sm-fold (Müller et al., 2019), frequently encountered in RNA-binding proteins like for example the bacterial RNA chaperone $\mathrm{Hfq}$ (host factor for RNA bacteriophage $\mathrm{Q} \beta$ replication) (Khusial et al., 2005; Updegrove et al., 2016). In Hfq, a highly conserved loop in the $\mathrm{Sm}-2$ region makes contact to the backbone of its RNA ligands (Schumacher et al., 2002; Khusial et al., 2005). Mutation of two arginine residues in the structurally homologous loop in $p a f B C$ renders it unable to rescue the mitomycin C-sensitive phenotype of the pafBC deletion strain (Müller et al., 2019). These results led to the suggestion that the proposed response-producing ligand is a nucleic acid molecule. Interestingly, bioinformatic analysis showed that transcriptional regulators featuring a winged helix-turn-helix domain followed by a WYL domain occur widely in bacteria, but not in eukaryotes (Müller et al., 2018). Indeed, it is likely that all WYL domain containing transcriptional regulators are activated according to a similar mechanism as PafBC.

The PafBC-mediated DNA damage response also plays a role for the action of fluoroquinolone antibiotics, which are important 
second-line drugs for treating multi-drug resistance tuberculosis infections. Fluoroquinolones target DNA gyrase and topoisomerase IV, causing the release of DNA with single or double strand breaks (Drlica et al., 2008). It was shown that a pafC deletion strain of $\mathrm{Msm}$ is strongly sensitized toward fluoroquinolone antibiotics ( $\mathrm{Li}$ et al., 2015). This finding makes sense in light of the fact that PafBC induces DNA repair genes involved in double-strand break repair (Müller et al., 2018). The fact that WYL-domain containing transcriptional regulators appear to be restricted to the bacterial kingdom (Müller et al., 2018), renders PafBC an attractive drug target, since PafBC inhibitors could be administered in combination with fluoroquinolone antibiotics to escalate their effect.

\section{The Pup-Proteasome System Supports Actinobacterial Survival Under Oxidative Stress}

Although the evolutionary origin of Actinobacteria predates oxygenation of the atmosphere (Battistuzzi et al., 2004), the majority of modern Actinobacteria are aerobic, where molecular oxygen serves as the final electron acceptor of the respiratory chain (Barka et al., 2016). Aerobic respiration has the advantage of high energy efficiency, however, partially reduced oxygen species occur as byproducts of aerobic metabolic activity. Endogenous production of superoxide $\left(\mathrm{O}_{2}^{-}\right)$and hydrogen peroxide $\left(\mathrm{H}_{2} \mathrm{O}_{2}\right)$ is largely due to autoxidation of flavoenzymes by transfer of electrons from the flavin cofactor to molecular oxygen (Imlay, 2003). In the presence of ferrous iron $\left(\mathrm{Fe}^{2+}\right)$, which is formed in the cellular environment from $\mathrm{Fe}^{3+}$ by reaction with $\mathrm{FADH}_{2}$ or cysteine as reductant, hydrogen peroxide can react to from hydroxyl radicals according to the Fenton reaction (Fenton, 1894). These reactive oxygen species (ROS) can cause DNA damage and protein modifications leading to loss of function (Cabiscol et al., 2000; Farout and Friguet, 2006). For this reason, bacteria are armed with detoxifying enzymes such as catalases, peroxiredoxins, and superoxide dismutases to combat these harmful agents. Mutants lacking these ROS detoxifying enzymes exhibit growth defects even under standard conditions, as ROS are continuously formed inside the cell as side products of metabolic reactions under aerobic conditions (Carlioz and Touati, 1986; Seaver and Imlay, 2001). In addition, bacteria may experience exogenous oxidative stress from their surrounding environment. Therefore, transcriptional and post-translational regulation mechanisms exist to respond to different levels of oxidative stress, controlling generation of protective redox molecules and expression of defense proteins or repair enzymes.

Eukaryotic proteasomes were shown early on to be involved in the removal of oxidized proteins (Farout and Friguet, 2006). Bacterial pupylation and proteasomal degradation has also been linked to counteracting oxidative stress. In this section, we will discuss where and when Actinobacteria encounter oxidative stress and how the PPS and PafBC regulon are involved in the oxidative stress response.
One major host defense strategy is the generation of ROS, reactive nitrogen species (RNS), and reactive chlorine species (RCS), which pathogenic bacteria must simultaneously contend with upon entering the host. A well-known example for such a hostile microenvironment are macrophages that are colonized by Mtb (Winterbourn et al., 2006; Flannagan et al., 2015). As mentioned previously in this review, a transposon mutagenesis screen in Mtb identified members of the PPS as being involved in RNS resistance (Darwin et al., 2003), linking the PPS to RNS stress before the pupylation pathway had been discovered. In the study, RNS stress was induced by exposing Mtb to $\mathrm{NaNO}_{2}$ at an acidic $\mathrm{pH}$ of 5.5 which led to significant survival reduction of $\mathrm{Mtb}$ lacking PPS components in comparison to wild type Mtb, while no phenotype was observed for these deletion strains under standard laboratory conditions (Darwin et al., 2003). Furthermore, it was shown in the mouse infection model that $\mathrm{Mtb}$ requires the proteasome to persist after infection (Gandotra et al., 2007). These studies established the PPS locus as relevant for survival of $\mathrm{Mtb}$ in the host and stimulated an interest in the proteasome as a drug target (Totaro et al., 2017).

An earlier study aimed at determining the protein targets of nitrosative stress identified $29 \mathrm{~S}$-nitrosylated proteins in Mtb exposed to sodium nitrite (Rhee et al., 2005), 24 of which were later also identified in studies determining the pupylated proteomes of Mtb or Msm (Festa et al., 2010; Poulsen et al., 2010; Watrous et al., 2010). Although this overlap is interesting considering one of the first stress conditions linked to the PPS was its protective effect against nitrosative stress (Darwin et al., 2003), it must be taken with caution, since no causal connection was made between nitrosylation and proteasomal degradation and since for none of those proteins an impaired function has been reported upon nitrosylation.

Curiously, the same study found that the Mtb PPS mutant strains were more resistant to hydrogen peroxide, a phenotype also observed in another study upon silencing of the proteasomal subunit genes (De Mot et al., 2007). Apart from Mtb, the PPS has also been investigated under different oxidative stresses in other Actinobacteria. A proteome analysis in S. coelicolor revealed the accumulation and depletion of proteins in mutants lacking ARC, Dop, Pup or the proteasome, respectively (De Mot et al., 2007). Interestingly, the mutants show increased resistance to cumene hydroperoxide that coincides with the accumulation of haloperoxidase SCO0465 in all of the mutants which could explain the hyper resistance of the mutants. Notably, hyper resistance was not observed for the mutant lacking ARC if oxidative stress was induced with diamide or plumbagin while the dop, pup, and proteasome deficient strains show similar hyper resistance. In 2015 two independent studies showed that genetic deletion of pup leads to $\mathrm{H}_{2} \mathrm{O}_{2}$ hypersensitivity in $\mathrm{S}$. coelicolor. One study observed that the $\mathrm{H}_{2} \mathrm{O}_{2}$ tolerance of the strain disrupted in $\operatorname{prcB}$ was comparable to that of the wild type strain rather than the pup knockout strain, which might indicate a proteasomeindependent role of pupylation in oxidative stress defense in $S$. coelicolor (Boubakri et al., 2015). In contrast, the other study reported $\mathrm{H}_{2} \mathrm{O}_{2}$ hypersensitive phenotypes for $\Delta p r c$ (SCO1643-1644), $\Delta p p s$ (SCO1643-1646, lacking Pup and the proteasomal subunit genes) and $\triangle p a f A$ (SCO1640) strains 
(Compton et al., 2015). However, their pafA knockout exhibits a sporulation defect while their prc and pps knockouts do not, which would support a role of pupylation acting independent of proteasomal degradation in this specific context (Compton et al., 2015). In those studies, the exact mechanism of how pupylation contributes to overcoming oxidative stress in S. coelicolor remains unclear.

Besides DNA damage repair pathway genes, the PafBC regulon comprises genes involved in the oxidative stress response. As mentioned in the previous section on the DNA damage response, this includes the ergothioneine biosynthesis gene cluster egtABCDE that encodes a secreted antioxidant low molecular weight thiol (Müller et al., 2018). Ergothioneine scavenges hydroxyl radicals and detoxifies peroxynitrite due to its high redox potential (Akanmu et al., 1991; Cumming et al., 2018). Hence, ergothioneine is essential for Mtb survival in macrophages because of its protective properties against oxidative and nitrosative stress (Richard-Greenblatt et al., 2015). Furthermore, ergothioneine acts as metal chelator blocking copper-induced oxidation of DNA (Zhu et al., 2011). Interestingly, the PPS also appears to be involved in shutting down the upregulation of ergothioneine biosynthesis, as EgtC and EgtD were identified as pupylation substrates during DNA stress (Müller et al., 2018). In addition to the ergothioneine gene cluster, two sigma factors involved in stress responses are contained in the PafBC regulon; SigH is activated upon heat shock, oxidative stress, and nitric oxide stress and induces transcription of thioredoxin, methionine sulfoxide reductase and chaperones such as Hsp70/DnaK (Sharp et al., 2016). The other sigma factor in the PafBC regulon is SigG which is known to play a role in Mtb during infection of host macrophages, however, its regulon is less well understood (Cappelli et al., 2006; Gaudion et al., 2013). Another protein of the PafBC regulon, the IscS-like cysteine desulfurase, removes sulfur from cysteine to produce alanine and a thiol group required for Fe-S core formation and is also involved in the oxidative stress response (Rybniker et al., 2014).

Taken together, the studies in mycobacteria and other Actinobacteria show that the PPS gene locus supports bacteria under oxidative stress, that the observed phenotypes are multicausal and that there are facets of the roles played by the PPS under oxidative conditions that remain to be discovered.

\section{Role of Pupylation in Actinobacterial Metal Homeostasis}

Many enzymes involved in fundamental biological processes require metals as cofactors for their catalytic activity (Andreini et al., 2008). In fact, such metalloenzymes constitute about onethird of all known enzymes (Holm et al., 1996). Iron ions are amongst the most abundant cofactors and found in a wide variety of enzymes playing a role in amino acid and pyrimidine biogenesis, the tricarboxylic acid cycle, electron transport, oxygen sensing and transport, as well as nucleic acid synthesis (Barton et al., 2007; Silva-Gomes et al., 2013). Therefore, iron is pivotal for almost all living organisms with only few exceptions (Posey and Gherardini, 2000). Iron ions exist in one of two redox states under physiological conditions: the reduced, highly watersoluble $\mathrm{Fe}^{2+}$ ferrous form is capable of forming toxic radicals and is predominantly found under anaerobic conditions and at low $\mathrm{pH}$; the oxidized, highly insoluble $\mathrm{Fe}^{3+}$ ferric form that is nontoxic and most prevalent under aerobic conditions. Iron homeostasis in the cell is tightly regulated and excess iron ions in the cytosol are stored as ferric oxide inside the iron storage protein bacterioferritin, a homo-24-meric cage able to hold up to 4,500 iron atoms (Andrews, 1998; Kurthkoti et al., 2015). Iron ions can be released from bacterioferritin when free iron levels become limiting to ensure that the enzymatic processes requiring this cofactor can be supported. In addition to the release of stored iron, Actinobacteria have evolved specialized mechanisms to overcome iron limitation; for example the secretion of iron chelators, so-called siderophores, that scavenge iron from the environment (Wang et al., 2014), which is for example crucial during Mtb infection (Rodriguez and Smith, 2006). The mechanisms of iron acquisition by siderophores and other iron uptake mechanisms such as heme uptake through hemophores, sequestration of holo-transferrin and hololactoferrin, as well as iron diffusion through low-affinity porins have been extensively reviewed (Banerjee et al., 2011; Ratledge, 2013; Fang et al., 2015; Chao et al., 2019). Here, we will describe the role of pupylation in iron homeostasis in Actinobacteria.

A study in the soil-based Gram-positive actinobacterium Corynebacterium glutamicum showed that mobilization of iron stores under iron limitation is dependent on pupylation (Küberl et al., 2016). Bacterioferritin Ftn was identified as a pupylation target and C. glutamicum pup, pafA and dop knockout strains showed growth defects in iron-limited medium (Küberl et al., 2014; Küberl et al., 2016). Interestingly, C. glutamicum lacks the proteasomal subunits $\operatorname{prcBA}$ which indicates degradationindependent iron release from Ftn. The authors propose a mechanism in which pupylated Ftn is unfolded by ARC leading to disassembly of the 24-mer and iron release. Monomeric Ftn is then recycled by Dop and can enter a new cycle of oligomerization and storage of iron. In addition, microarrays showed that mRNA levels of iron-dependent proteins were significantly depleted in the pup knockout strain suggesting that pupylation of Ftn is also indirectly involved in other aspects of iron homeostasis. It is still unclear how many Ftn subunits need to be pupylated for successful disassembly and how iron is solubilized from the mineral core (Küberl et al., 2016).

This study is a prime example of pupylation and unfolding in cellular homeostasis in the absence of the $20 \mathrm{~S}$ proteasome. Nevertheless, the sensing trigger for pupylation of Ftn in $C$. glutamicum is not known to date. The study also raises the question about potential other proteasome-independent roles of pupylation. According to a pupylome study performed in $\mathrm{Msm}, \mathrm{BfrB}$ is pupylated at the conserved lysine residue $\mathrm{K} 10$ (Watrous et al., 2010). Pupylation of BfrB could not be detected in Mtb by mass-spectrometry, but is observed in two independent pupylomes in Msm (Festa et al., 2010; Poulsen et al., 2010). This might suggest the Ftn homolog BfrB in mycobacteria could be a degradation substrate. However, this has not been demonstrated 
directly and it remains possible that Mpa can act on its own as in C. glutamicum.

Copper is another essential micronutrient in living organisms required for activity of multiple enzymes involved in electron transport, denitrification and oxidative respiration (Tavares et al., 2006). Yet, copper homeostasis needs to be tightly regulated since copper is toxic in high concentrations due to ROS generation (Dennison et al., 2018). Interestingly, one of the macrophage defense mechanisms is the accumulation of copper within the phagosome upon mycobacterial infection (Wagner et al., 2006). The PPS was linked to copper homeostasis for the first time through a transcriptional screen that compared the Mtb mutant strains disrupted in the gene coding for the Pup ligase ( $p a f A$ ) or the gene coding for the proteasomal ATPase $(m p a)$ with wild type Mtb (Festa et al., 2011). Of 4009 predicted open reading frames fewer than $2 \%$ of the genes showed differential expression in the pafA and mpa disrupted strains compared to the wild type. One of those genes is the copper sensing repressor RicR that contributes to virulence of Mtb (Festa et al., 2011; Shi et al., 2014). Interestingly, RicR transcript levels are downregulated in pafA and mpa disrupted strains compared to wild type Mtb. However, RicR does not accumulate in pupylation deficient strains under all tested growth conditions so far (Festa et al., 2011) and has not been identified in any of the pupylomes. The authors hypothesize that transcriptional RicR downregulation in the pupylation deficient strains might be a downstream result of the accumulation of copper-binding proteins that are pupylation substrates. In turn, accumulation of copper-binding proteins might mimic copper limiting conditions that lead to RicR repression (Festa et al., 2011). However, pupylation candidates leading to the potential downstream event of RicR repression are currently lacking.

\section{CONTRIBUTION OF PUPYLATION-INDEPENDENT PROTEASOMAL DEGRADATION TO ACTINOBACTERIAL STRESS RESPONSES}

Bacterial stress responses are as diverse as the environmental insults that threaten the survival of the bacteria. One environmental parameter that has the ability to affect a multitude of cellular processes simultaneously is high temperature. Proteins mediate the majority of cellular reactions and pathways and as such affect essentially every aspect of cellular function. Their individual activity is supported not only by their primary sequence, but also by the precise three-dimensional structures they adopt and the complexes they form. When ambient temperature suddenly increases, cellular proteins can misfold, adopt inactive conformations or aggregate, leading to loss of function and threatening survival (Lewis and Pelham, 1985; Pelham, 1986). Thus, bacteria are equipped with intricate regulatory mechanisms to induce the expression of heat shock chaperones that are able to promote folding during heat stress as a way to quickly adapt to this challenging environment (Lewis and Pelham, 1985; Pelham,

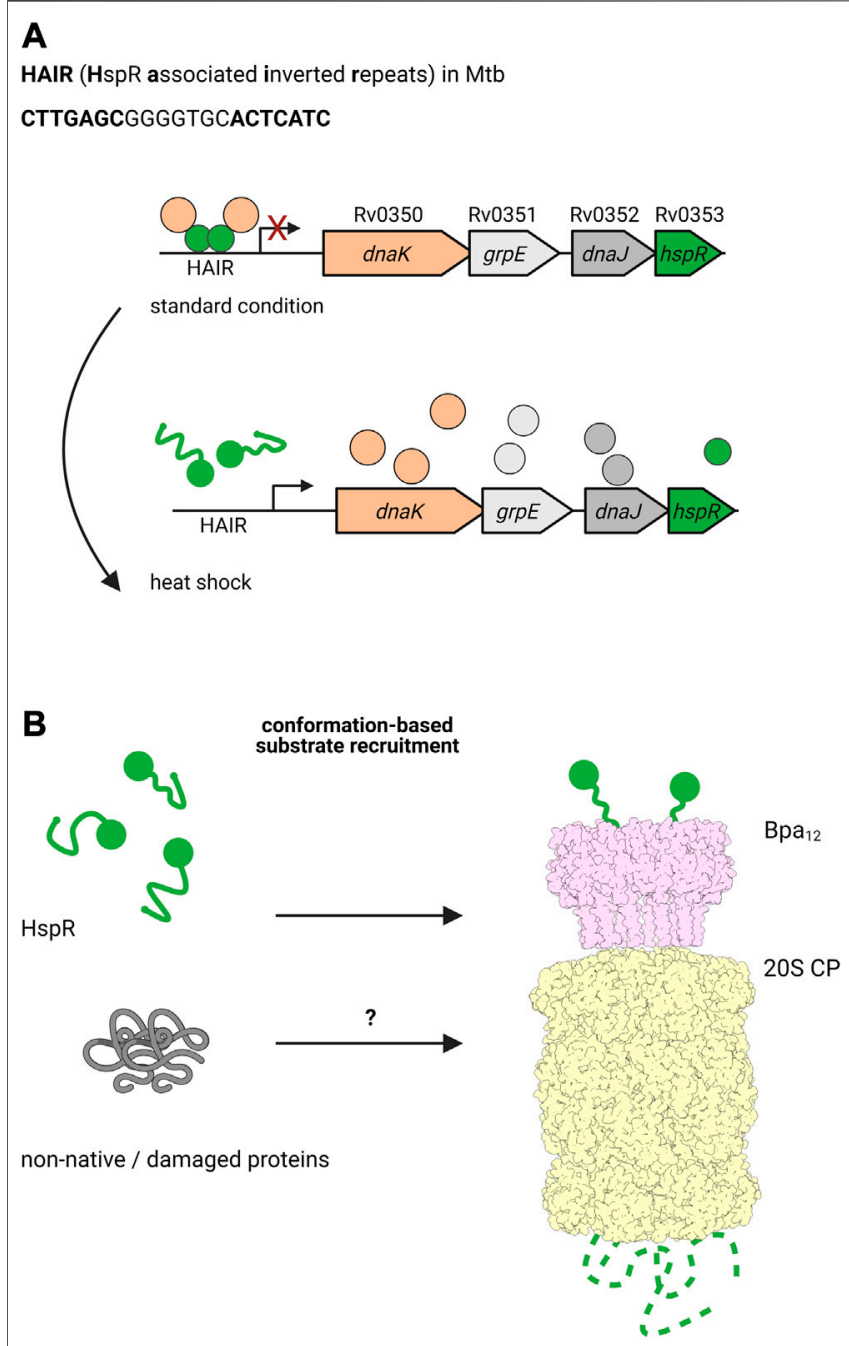

FIGURE 4 | The ATP-independent proteasomal activator Bpa plays a role during heat shock in Mtb. (A) Under standard conditions, the heat shock chaperone DnaK co-represses the transcription of the dnaKJgrpE-hspR operon together with the transcriptional regulator $\mathrm{HspR}$, which binds the HAIR motif operator. Upon heat shock, HspR is partially denatured and dissociates off the promoter to allow transcription of $d n a K$, grpE, dnaJ and $h s p R$, ultimately leading to production of the encoded proteins. (B) $\mathrm{HspR}$ (green) is a substrate for the ATP- and pupylation-independent proteasomal degradation facilitated by Bpa (light pink). Bpa assembles into a homododecameric ring and interacts with the $20 \mathrm{~S}$ proteasome (light yellow) by inserting its C-terminal GQYL motif into binding pockets between the a-subunits of the core particle. Though there is no overall homology to Mpa/ ARC, the GQYL motif is shared between both proteasomal activators.

1986; Hartl, 1996). Two major chaperone machineries in the bacterial cytosol are the GroEL/GroES and the DnaKJ/GrpE chaperone systems that are under positive control by sigma factors in E. coli, yet negatively regulated in several Grampositive bacteria including Streptomyces and in mycobacteria (Bukau and Horwich, 1998; Narberhaus, 1999; Stewart et al., 2001; Bucca et al., 2003). GroEL and DnaK belong to the Hsp60 and Hsp70 family, respectively (Horwich and Fenton, 2020). In $\mathrm{Mtb}$, there are two groEL loci (Rv0440 and Rv3417c), both controlled by the repressor HrcA (Stewart et al., 2002b), which 
is a pupylation substrate, hence linking the chaperone system to the PPS as discussed already in a previous section of this review.

It has been shown that the alternative degradation complex, formed by the bacterial proteasome with ATP-independent, ringshaped activator $\mathrm{Bpa}$, is involved in regulation of the DnaK operon in Mtb (Jastrab et al., 2015; Jastrab et al., 2017). In mycobacteria, transcription of dnaK is controlled by heat shock repressor HspR (Stewart et al., 2002b; Stewart et al., 2001; Stewart et al., 2002a). Under normal conditions, HspR binds to its operator, the HAIR motif (HspR associated inverted repeats), to repress the expression of $d n a K$, its co-chaperone $d n a J$, the exchange factor $g r p E$ and $h s p R$ itself (Bucca et al., 1995; Bucca et al., 1997). Interestingly, DnaK binds HspR acting as corepressor, and upon heat shock, the complex detaches to allow the expression of these heat shock chaperones (Figure 4) (Bucca et al., 2000; Bandyopadhyay et al., 2012; Parijat and Batra, 2015). In addition to DnaK and the other proteins expressed in the dnaKJEhspR operon, HspR also regulates the expression of chaperone genes $\operatorname{clp} B$ and $a c r 2$, which belong to the Hsp100 and Hsp20 family, respectively (Grandvalet et al., 1999). HspR is one of the few known proteasomal substrates that is recruited by the pupylation-independent activator Bpa (also called PafE) for proteasomal degradation (Figure 4) (Jastrab et al., 2015).

Bpa was first identified by a full genome search in $\mathrm{Mtb}$ for genes that feature a C-terminal motif similar to the proteasome interaction motif found at the C-termini of Mpa (Delley et al., 2014). Though otherwise lacking any structural or sequence homology with Mpa, Bpa contains the same GQYL sequence at the C-terminus that in Mpa mediates binding to the $\alpha$-subunits of the $20 \mathrm{~S}$ proteasome. Bpa occurs in every actinobacterial species containing the $20 \mathrm{~S}$ proteasome, but is absent in all Actinobacteria lacking the proteasomal subunits. Biochemical analysis demonstrated that Bpa forms a homooligomeric ring and is able to interact with the wild type $20 \mathrm{~S}$ proteasome to degrade substrate in a pupylation and ATP-independent manner. Structural studies showed that Bpa, unlike the hexameric $\mathrm{Mpa}$, forms a dodecameric ring with a funnellike opening (Bolten et al., 2016; Hu et al., 2018).

ATP-independent activators were already known for the eukaryotic proteasome, where they were also shown to recruit substrates independent of ubiquitination. It has been hypothesized that disorder and low substrate stability may be substrate determinants, as supported by the degradation of the unstructured tau protein by the PA200 proteasomal activator in complex with the 20 S proteasome in vitro (Huang et al., 2016). Similarly, it was shown that in bacteria, Bpa is able to facilitate the proteasomal degradation of the model substrate $\beta$-casein (Delley et al., 2014), which is used to mimic unstructured proteins due to its extended non-globular structure. This led to the hypothesis that upon stress induction, cytosolic proteins may become damaged or denatured, rendering them targets for Bpa-mediated proteasomal degradation. Indeed an Mtb $b p a$ knockout strain showed a heat sensitive phenotype when grown at $45{ }^{\circ} \mathrm{C}$ (Jastrab et al., 2015). However, the authors also observed that $d n a K$ and $c l p B$ mRNA levels dropped, suggesting that the phenotype is due to accumulating HspR that represses $d n a K$ and $c l p B$ transcription to a higher extent. This in turn would have an impact on the quality control of the bacterium under stress. However, the two might not have to be mutually exclusive. Bpa might be involved in two aspects of the heat shock response: the regulation of heat shock response through proteasomal degradation of $\mathrm{HspR}$ and the removal of non-native proteins damaged during heat stress. Interestingly, loss of function mutations reversing the heatsensitive phenotype of the $b p a$ knockout strain were found in the HspR DNA binding domain (Jastrab et al., 2017). In addition to heat shock, it was suggested that Bpa also plays a vital role in Mtb virulence, as a $b p a$ knockout strain was attenuated in mouse lungs and spleens (Jastrab et al., 2015). Hence, Bpa may play a role in other important stress responses that is yet to be discovered.

Although association with other ATP-dependent proteases could be preferred pathways to rid the cell of damaged or nonnative substrates, it has been suggested that Bpa could have an important role under stressful conditions when ATP becomes limiting, for example during oxygen or nutrient limitation (Jastrab et al., 2017). Other stresses have yet to be tested and the heat shock sensitivity of a $b p a$ knockout strain has only been seen in Mtb to date.

Recently, a new pupylation independent proteasomal interactor was identified (Ziemski et al., 2018). The Cdc48-like protein of Actinobacteria (Cpa) is a hexameric ATPase, like Mpa, and interacts with the wild type $20 \mathrm{~S}$ proteasome in vitro. Cpa is homologous to the AAA protein $\mathrm{Cdc} 48$ in eukaryotes that, in coordination with the eukaryotic proteasome and various cofactors, is involved in multiple biological processes (Baek et al., 2013). Though best known for its involvement in ER-associated degradation (ERAD), eukaryotic Cdc48 plays vital roles in many other biological functions extensively reviewed elsewhere (Wolf and Stolz, 2012; Yamanaka et al., 2012; Baek et al., 2013).

Similar to Bpa, Cpa occurrence has only been shown in Actinobacteria that also harbor the genes for the $\alpha$ - and $\beta$-subunits of the $20 \mathrm{~S}$ proteasome. Although Cpa competes with Mpa for binding to the $20 \mathrm{~S}$ proteasome in vitro, no substrates have yet been found for Cpa-mediated proteasomal degradation. Notably, Cpa does not feature the conserved C-terminal GQYL interaction motif found both in $\mathrm{Mpa}$ and $\mathrm{Bpa}$, and the interaction determinants are poorly understood (Ziemski et al., 2018).

The only information available to date on the role of Cpa comes from in vivo studies, which were carried out in Msm. In a cpa knockout strain in Msm, a mild phenotype was observed under carbon starvation, suggesting that Cpa may be involved in stress conditions where nutrients like carbon are limited. Bacteria in nature can often be starved of carbon, for example in marine environments where the carbon concentration is significantly lower or is in a bio-unavailable form (Morita, 1988). In the soil, carbon is also not always found in a state that can be readily incorporated (Lockwood, 1977).

Comparative proteomic analysis of the Msm cpa knockout showed significant accumulation of proteins involved in translation and ribosomal biogenesis. One possibility is that Cpa, in complex with the $20 \mathrm{~S}$ proteasome, plays a role in disassembly and removal of ribosomal proteins under nutrient limited conditions. However, biochemical data is currently lacking to support this hypothesis and additional studies are required to understand the 
molecular basis of this phenotype. It is also possible that, like its eukaryotic counterpart Cdc48, Cpa is additionally involved in cellular pathways not dependent on proteasomal degradation.

\section{CONCLUDING REMARKS}

The Pup-proteasome gene locus of Actinobacteria provides this large and diverse group of organisms with an advantage to grow and proliferate under the demanding and rapidly changing conditions they encounter in their natural surroundings. In all actinobacterial species investigated to date, phenotypes are observed under a variety of stress conditions but growth is normal or only very mildly affected under standard laboratory culture conditions. In complex with different ring-shaped activators, the $20 \mathrm{~S}$ proteasome supports the survival of Actinobacteria in hostile conditions, including starvation, reactive nitrogen intermediates, oxidative stress, and heat shock.

Although these stresses on the surface appear to represent separate challenges and occur as a consequence of different events, they present an interwoven network of effects on various aspects of actinobacterial biology, and response mechanisms to one kind of stress also play a role during other experienced insults. The mechanistic complexity of PPS involvement in these stress responses is beginning to emerge. For example, oxidative stress due to ROS can cause irreversible protein modifications and the $20 \mathrm{~S}$ proteasome is thought to be involved in removal of these aberrant proteins. However, oxidative stress can also lead to DNA damage through double stranded breaks, causing PafBC to activate the LexA/RecA-independent DNA damage response pathway. Furthermore, the two proteasomal degradation pathways, the pupylation-mediated and the Pup-independent pathway, can address the same stress from different directions. For example, the PPS is involved in the expression of two major chaperone machineries, the DnaKJGrpE and the GroELS chaperone systems, which are important for bacteria to adapt to stress like temperature shock. In complex with the ATP-independent activator Bpa that recruits substrates independent of pupylation, the $20 \mathrm{~S}$ proteasome degrades the repressor HspR to allow for expression of the dnaK operon. On the other hand, HrcA responsible for repressing the groEL1, groEL2, and groES genes, is a pupylation substrate and is degraded by the $20 \mathrm{~S}$ proteasome in complex with Mpa. In addition,

\section{REFERENCES}

Agapova, A., Serafini, A., Petridis, M., Hunt, D. M., Garza-Garcia, A., Sohaskey, C. D., et al. (2019). Flexible Nitrogen Utilisation by the Metabolic Generalist Pathogen Mycobacterium tuberculosis. Elife 8, e41129. doi:10.7554/elife.41129 Akanmu, D., Cecchini, R., Aruoma, O. I., and Halliwell, B. (1991). The Antioxidant Action of Ergothioneine. Arch. Biochem. Biophys. 288 (1), 10-16. doi:10.1016/ 0003-9861(91)90158-f

Amon, J., Titgemeyer, F., and Burkovski, A. (2009). A Genomic View on Nitrogen Metabolism and Nitrogen Control in Mycobacteria. J. Mol. Microbiol. Biotechnol. 17 (1), 20-29. doi:10.1159/000159195

Andreini, C., Bertini, I., Cavallaro, G., Holliday, G. L., and Thornton, J. M. (2008). Metal Ions in Biological Catalysis: From Enzyme Databases to General Principles. J. Biol. Inorg. Chem. 13 (8), 1205-1218. doi:10.1007/s00775-008-0404-5
GroEL is necessary for proper folding of nitrite reductase NirBD, linking the PPS to nitrogen metabolism and nitrosative stress. The versatility of the bacterial $20 \mathrm{~S}$ proteasome, shown by its ability to interact with multiple activators to promote survival of Actinobacteria under different stresses, demonstrates that it plays an important role in the complex actinobacterial stress response and quality control pathways.

Given its involvement in various stress response pathways that are relevant to the survival of Mtb inside macrophages, the proteasome and other members of the PPS locus constitute attractive drug targets for treatment of $\mathrm{Mtb}$ infections. In fact, multiple inhibitors against the Mtb 20S proteasome have been designed and shown to make Mtb susceptible to its host's immune system without heavily disrupting function of the eukaryotic proteasome (Totaro et al., 2017). With the emergence of multi-resistant and even completely resistant $\mathrm{Mtb}$ strains, new avenues to treat $\mathrm{Mtb}$ infections are urgently needed. Already today, combination therapies are usually used to treat Mtb patients. Drugs targeting the PPS could be another weapon in this arsenal, and could help to thwart the bacterium's efforts to survive interventions by the host immune system and drug therapy.

\section{AUTHOR CONTRIBUTIONS}

TvR, LK, and EW-B contributed to drafting, writing and editing of the manuscript.

\section{FUNDING}

The authors are supported by the Swiss National Science Foundation (SNSF grant 310030_185250) ETH research grant (ETH-17 17-2).

\section{ACKNOWLEDGMENTS}

We would like to thank the Weber-Ban group, especially Matthias Block and Andreas Müller for critical reading of the manuscript. All figures were created with BioRender.com.

Andrews, S. C. (1998). Iron Storage in Bacteria. Adv. Microb. Physiol. 40, 281-351. doi:10.1016/s0065-2911(08)60134-4

Awuh, J. A., and Flo, T. H. (2017). Molecular Basis of Mycobacterial Survival in Macrophages. Cell. Mol. Life Sci. 74 (9), 1625-1648. doi:10.1007/s00018-0162422-8

Baek, G. H., Cheng, H., Choe, V., Bao, X., Shao, J., Luo, S., et al. (2013). Cdc48: A Swiss Army Knife of Cell Biology. J. Amino Acids 2013, 183421. doi:10.1155/ 2013/183421

Bandyopadhyay, B., Das Gupta, T., Roy, D., and Das Gupta, S. K. (2012). DnaK Dependence of the Mycobacterial Stress-Responsive Regulator HspR Is Mediated through its Hydrophobic C-Terminal Tail. J. Bacteriol. 194 (17), 4688-4697. doi:10.1128/jb.00415-12

Banerjee, S., Farhana, A., Ehtesham, N. Z., and Hasnain, S. E. (2011). Iron Acquisition, Assimilation and Regulation in Mycobacteria. Infect. Genet. Evol. 11 (5), 825-838. doi:10.1016/j.meegid.2011.02.016 
Barandun, J., Damberger, F. F., Delley, C. L., Laederach, J., Allain, F. H. T., and Weber-Ban, E. (2017). Prokaryotic Ubiquitin-like Protein Remains Intrinsically Disordered when Covalently Attached to Proteasomal Target Proteins. Bmc Struct. Biol. 17, 1. doi:10.1186/s12900-017-0072-1

Barandun, J., Delley, C. L., Ban, N., and Weber-Ban, E. (2013). Crystal Structure of the Complex between Prokaryotic Ubiquitin-like Protein and its Ligase PafA. J. Am. Chem. Soc. 135 (18), 6794-6797. doi:10.1021/ja4024012

Barka, E. A., Vatsa, P., Sanchez, L., Gaveau-Vaillant, N., Jacquard, C., Klenk, H.-P., et al. (2016). Taxonomy, Physiology, and Natural Products of Actinobacteria. Microbiol. Mol. Biol. Rev. 80 (1), 1-43. doi:10.1128/mmbr.00019-15

Barton, L. L., Goulhen, F., Bruschi, M., Woodards, N. A., Plunkett, R. M., and Rietmeijer, F. J. M. (2007). The Bacterial Metallome: Composition and Stability with Specific Reference to the Anaerobic Bacterium Desulfovibrio Desulfuricans. BioMetals 20, 291-302. doi:10.1007/s10534-006-9059-2

Battistuzzi, F. U., Feijao, A., and Hedges, S. B. (2004). A Genomic Timescale of Prokaryote Evolution: Insights into the Origin of Methanogenesis, Phototrophy, and the Colonization of Land. BMC Evol. Biol. 4, 44. doi:10. 1186/1471-2148-4-44

Becker, S. H., Jastrab, J. B., Dhabaria, A., Chaton, C. T., Rush, J. S., Korotkov, K. V., et al. (2019). TheMycobacterium tuberculosisPup-Proteasome System Regulates Nitrate Metabolism through an Essential Protein Quality Control Pathway. Proc. Natl. Acad. Sci. USA 116 (8), 3202-3210. doi:10.1073/pnas. 1819468116

Benoist, P., Müller, A., Diem, H. G., and Schwencke, J. (1992). High-molecularmass Multicatalytic Proteinase Complexes Produced by the Nitrogen-Fixing Actinomycete Frankia Strain BR. BR. J. Bacteriol. 174 (5), 1495-1504. doi:10. 1128/jb.174.5.1495-1504.1992

Bolten, M., Delley, C. L., Leibundgut, M., Boehringer, D., Ban, N., and Weber-Ban, E. (2016). Structural Analysis of the Bacterial Proteasome Activator Bpa in Complex with the 20S Proteasome. Structure 24 (12), 2138-2151. doi:10.1016/j. str.2016.10.008

Bolten, M., Vahlensieck, C., Lipp, C., Leibundgut, M., Ban, N., and Weber-Ban, E. (2017). Depupylase Dop Requires Inorganic Phosphate in the Active Site for Catalysis. J. Biol. Chem. 292 (10), 4044-4053. doi:10.1074/jbc.m116.755645

BoseDasgupta, S., and Pieters, J. (2018). Macrophage-microbe Interaction: Lessons Learned from the Pathogen Mycobacterium tuberculosis. Semin. Immunopathol 40 (6), 577-591. doi:10.1007/s00281-018-0710-0

Boubakri, H., Seghezzi, N., Duchateau, M., Gominet, M., Kofroňová, O., Benada, O., et al. (2015). The Absence of Pupylation (Prokaryotic Ubiquitin-like Protein Modification) Affects Morphological and Physiological Differentiation in Streptomyces Coelicolor. J. Bacteriol. 197 (21), 3388-3399. doi:10.1128/jb. 00591-15

Bucca, G., Brassington, A. M., Schönfeld, H. J., and Smith, C. P. (2000). The HspR Regulon of Streptomyces Coelicolor: a Role for the DnaK Chaperone as a Transcriptional Co-repressordagger. Mol. Microbiol. 38 (5), 1093-1103. doi:10. 1046/j.1365-2958.2000.02194.x

Bucca, G., Brassington, A. M. E., Hotchkiss, G., Mersinias, V., and Smith, C. P. (2003). Negative Feedback Regulation of dnaK, clpB and Lon Expression by the DnaK Chaperone Machine in Streptomyces Coelicolor, Identified by Transcriptome and In Vivo DnaK-Depletion Analysis. Mol. Microbiol. 50 (1), 153-166. doi:10.1046/j.1365-2958.2003.03696.x

Bucca, G., Ferina, G., Puglia, A. M., and Smith, C. P. (1995). The dnaK Operon of Streptomyces Coelicolor Encodes a Novel Heat-Shock Protein Which Binds to the Promoter Region of the Operon. Mol. Microbiol. 17 (4), 663-674. doi:10. 1111/j.1365-2958.1995.mmi_17040663.x

Bucca, G., Hindle, Z., Smith, C. P., Hindle, Z., and Smith, C. P. (1997). Regulation of the dnaK Operon of Streptomyces Coelicolor A3(2) Is Governed by HspR, an Autoregulatory Repressor Protein. J. Bacteriol. 179 (19), 5999-6004. doi:10. 1128/jb.179.19.5999-6004.1997

Bukau, B., and Horwich, A. L. (1998). The Hsp70 and Hsp60 Chaperone Machines. Cell 92 (3), 351-366. doi:10.1016/s0092-8674(00)80928-9

Burns, K. E., Cerda-Maira, F. A., Wang, T., Li, H., Bishai, W. R., and Darwin, K. H. (2010). "Depupylation" of Prokaryotic Ubiquitin-like Protein from Mycobacterial Proteasome Substrates. Mol. Cel 39 (5), 821-827. doi:10.1016/ j.molcel.2010.07.019

Burns, K. E., Liu, W.-T., Boshoff, H. I. M., Dorrestein, P. C., and Barry, C. E. (2009). Proteasomal Protein Degradation in Mycobacteria Is Dependent upon a
Prokaryotic Ubiquitin-like Protein. J. Biol. Chem. 284 (5), 3069-3075. doi:10.1074/jbc.m808032200

Butala, M., Klose, D., Hodnik, V., Rems, A., Podlesek, Z., Klare, J. P., et al. (2011). Interconversion between Bound and Free Conformations of LexA Orchestrates the Bacterial SOS Response. Nucleic Acids Res. 39 (15), 6546-6557. doi:10.1093/ nar/gkr265

Cabiscol, E., Tamarit, J., and Ros, J. (2000). Oxidative Stress in Bacteria and Protein Damage by Reactive Oxygen Species. Int. Microbiol. 3 (1), 3-8.

Cappelli, G., Volpe, E., Grassi, M., Liseo, B., Colizzi, V., and Mariani, F. (2006). Profiling of Mycobacterium tuberculosis Gene Expression during Human Macrophage Infection: Upregulation of the Alternative Sigma Factor G, a Group of Transcriptional Regulators, and Proteins with Unknown Function. Res. Microbiol. 157 (5), 445-455. doi:10.1016/j.resmic.2005.10.007

Carlioz, A., and Touati, D. (1986). Isolation of Superoxide Dismutase Mutants in Escherichia coli: Is Superoxide Dismutase Necessary for Aerobic Life?. EMBO J. 5 (3), 623-630. doi:10.1002/j.1460-2075.1986. tb04256.x

Cerda-Maira, F. A., Pearce, M. J., Fuortes, M., Bishai, W. R., Hubbard, S. R., and Darwin, K. H. (2010). Molecular Analysis of the Prokaryotic Ubiquitin-like Protein (Pup) Conjugation Pathway in Mycobacterium tuberculosis. Mol. Microbiol. 77 (5), 1123-1135. doi:10.1111/j.1365-2958.2010.07276.x

Chao, A., Sieminski, P. J., Owens, C. P., and Goulding, C. W. (2019). Iron Acquisition inMycobacterium Tuberculosis. Chem. Rev. 119 (2), 1193-1220. doi:10.1021/acs.chemrev.8b00285

Chen, X., Solomon, W. C., Kang, Y., Cerda-Maira, F., Darwin, K. H., and Walters, K. J. (2009). Prokaryotic Ubiquitin-like Protein Pup Is Intrinsically Disordered. J. Mol. Biol. 392 (1), 208-217. doi:10.1016/j.jmb.2009.07.018

Compton, C. L., Fernandopulle, M. S., Nagari, R. T., and Sello, J. K. (2015). Genetic and Proteomic Analyses of Pupylation in Streptomyces Coelicolor. J. Bacteriol. 197 (17), 2747-2753. doi:10.1128/jb.00302-15

Cumming, B. M., Chinta, K. C., Reddy, V. P., and Steyn, A. J. C. (2018). Role of Ergothioneine in Microbial Physiology and Pathogenesis. Antioxid. Redox Signaling 28 (6), 431-444. doi:10.1089/ars.2017.7300

Darwin, K. H., Lin, G., Chen, Z., Li, H., and Nathan, C. F. (2005). Characterization of a Mycobacterium tuberculosis Proteasomal ATPase Homologue. Mol. Microbiol. 55 (2), 561-571. doi:10.1111/j.1365-2958.2004.04403.x

Darwin, K. H., Ehrt, S., Gutierrez-Ramos, J-C., Weich, N., and Nathan, C. F. (2003). The Proteasome of Mycobacterium tuberculosis Is Required for Resistance to Nitric Oxide. Science 302 (5652), 1963-1966. doi:10.1126/ science. 1091176

Davis, E. O., Springer, B., Gopaul, K. K., Papavinasasundaram, K. G., Sander, P., and Böttger, E. C. (2002). DNA Damage Induction of recA in Mycobacterium tuberculosis Independently of RecA and LexA. Mol. Microbiol. 46 (3), 791-800. doi:10.1046/j.1365-2958.2002.03199.x

De Mot, R., Schoofs, G., and Nagy, I. (2007). Proteome Analysis of Streptomyces Coelicolor Mutants Affected in the Proteasome System Reveals Changes in Stress-Responsive Proteins. Arch. Microbiol. 188 (3), 257-271. doi:10.1007/ s00203-007-0243-8

Delley, C. L., Laederach, J., Ziemski, M., Bolten, M., Boehringer, D., and WeberBan, E. (2014). Bacterial Proteasome Activator Bpa (Rv3780) Is a Novel RingShaped Interactor of the Mycobacterial Proteasome. PLoS One 9 (12), el14348. doi:10.1371/journal.pone.0114348

Delley, C. L., Müller, A. U., Ziemski, M., Weber-Ban, E., Muller, A. U., Ziemski, M., et al. (2017). Prokaryotic Ubiquitin-like Protein and its Ligase/Deligase Enyzmes. J. Mol. Biol. 429 (22), 3486-3499. doi:10.1016/j.jmb.2017. 04.020

Dennison, C., David, S., and Lee, J. (2018). Bacterial Copper Storage Proteins. J. Biol. Chem. 293 (13), 4616-4627. doi:10.1074/jbc.tm117.000180

Drlica, K., Malik, M., Kerns, R. J., and Zhao, X. (2008). Quinolone-mediated Bacterial Death. Aac 52 (2), 385-392. doi:10.1128/aac.01617-06

Elharar, Y., Roth, Z., Hermelin, I., Moon, A., Peretz, G., Shenkerman, Y., et al. (2014). Survival of Mycobacteria Depends on Proteasome-mediated Amino Acid Recycling under Nutrient Limitation. EMBO J. 33 (16), 1802-1814. doi:10. 15252/embj.201387076

Fang, F. C. (2004). Antimicrobial Reactive Oxygen and Nitrogen Species: Concepts and Controversies. Nat. Rev. Microbiol. 2 (10), 820-832. doi:10.1038/ nrmicro1004 
Fang, Z., Sampson, S. L., Warren, R. M., Gey van Pittius, N. C., and Newton-Foot, M. (2015). Iron Acquisition Strategies in Mycobacteria. Tuberculosis 95 (2), 123-130. doi:10.1016/j.tube.2015.01.004

Farout, L., and Friguet, B. (2006). Proteasome Function in Aging and Oxidative Stress: Implications in Protein Maintenance Failure. Antioxid. Redox Signaling 8 (1 \& 2), 205-216. doi:10.1089/ars.2006.8.205

Fascellaro, G., Petrera, A., Lai, Z. W., Nanni, P., Grossmann, J., Burger, S., et al. (2016). Comprehensive Proteomic Analysis of Nitrogen-Starved Mycobacterium Smegmatis $\Delta$ pup Reveals the Impact of Pupylation on Nitrogen Stress Response. J. Proteome Res. 15 (8), 2812-2825. doi:10.1021/ acs.jproteome.6b00378

Fenton, H. J. H. (1894). LXXIII.-Oxidation of Tartaric Acid in Presence of Iron. J. Chem. Soc. Trans. 65, 899-910. doi:10.1039/ct8946500899

Festa, R. A., Jones, M. B., Butler-Wu, S., Sinsimer, D., Gerads, R., Bishai, W. R., et al. (2011). A Novel Copper-Responsive Regulon in Mycobacterium tuberculosis. Mol. Microbiol. 79 (1), 133-148. doi:10.1111/j.1365-2958.2010.07431.x

Festa, R. A., McAllister, F., Pearce, M. J., Mintseris, J., Burns, K. E., Gygi, S. P., et al. (2010). Prokayrotic Ubiquitin-like Protein (Pup) Proteome of Mycobacterium tuberculosis. PLoS One 5 (1), e8589. doi:10.1371/journal.pone.0008589

Festa, R. A., Pearce, M. J., and Darwin, K. H. (2007). Characterization of the Proteasome Accessory Factor (Paf) Operon in Mycobacterium tuberculosis. J. Bacteriol. 189 (8), 3044-3050. doi:10.1128/jb.01597-06

Flannagan, R., Heit, B., and Heinrichs, D. (2015). Antimicrobial Mechanisms of Macrophages and the Immune Evasion Strategies of Staphylococcus aureus. Pathogens 4 (4), 826-868. doi:10.3390/pathogens4040826

Galletto, R., Amitani, I., Baskin, R. J., and Kowalczykowski, S. C. (2006). Direct Observation of Individual RecA Filaments Assembling on Single DNA Molecules. Nature 443 (7113), 875-878. doi:10.1038/nature05197

Gamulin, V., Cetkovic, H., and Ahel, I. (2004). Identification of a Promoter Motif Regulating the Major DNA Damage Response Mechanism ofMycobacterium Tuberculosis. FEMS Microbiol. Lett. 238 (1), 57-63. doi:10.1111/j.1574-6968. 2004.tb09737.x

Gandotra, S., Schnappinger, D., Monteleone, M., Hillen, W., and Ehrt, S. (2007). In vivo gene Silencing Identifies the Mycobacterium tuberculosis Proteasome as Essential for the Bacteria to Persist in Mice. Nat. Med. 13 (12), 1515-1520. doi: $10.1038 / \mathrm{nm} 1683$

Gaudion, A., Dawson, L., Davis, E., and Smollett, K. (2013). Characterisation of the mycobacterium Tuberculosis Alternative Sigma Factor SigG: Its Operon and Regulon. Tuberculosis 93 (5), 482-491. doi:10.1016/j.tube.2013.05.005

Gerth, U., Kock, H., Kusters, I., Michalik, S., Switzer, R. L., and Hecker, M. (2008). Clp-dependent Proteolysis Down-Regulates Central Metabolic Pathways in Glucose-Starved Bacillus Subtilis. J. Bacteriol. 190 (1), 321-331. doi:10.1128/jb. 01233-07

Giese, K. C., Michalowski, C. B., and Little, J. W. (2008). RecA-Dependent Cleavage of LexA Dimers. J. Mol. Biol. 377 (1), 148-161. doi:10.1016/j. jmb.2007.12.025

Grandvalet, C., de Crecy-Lagard, V., Mazodier, P., De Crécy-Lagard, V., Mazodier, P., Rie De Cré Cy-Lagard, V., et al. (1999). The ClpB ATPase of Streptomyces Albus G Belongs to the HspR Heat Shock Regulon. Mol. Microbiol. 31 (2), 521-532. doi:10.1046/j.1365-2958.1999.01193.x

Guo, M. S., and Gross, C. A. (2014). Stress-induced Remodeling of the Bacterial Proteome. Curr. Biol. 24 (10), R424-R434. doi:10.1016/j.cub.2014. 03.023

Guth, E., Thommen, M., and Weber-Ban, E. (2011). Mycobacterial Ubiquitin-like Protein Ligase PafA Follows a Two-step Reaction Pathway with a Phosphorylated Pup Intermediate. J. Biol. Chem. 286 (6), 4412-4419. doi:10. 1074/jbc.m110.189282

Hartl, F. U. (1996). Molecular Chaperones in Cellular Protein Folding. Nature 381 (6583), 571-580. doi:10.1038/381571a0

Haruta, S., and Kanno, N. (2015). Survivability of Microbes in Natural Environments and Their Ecological Impacts. Microb. Environ. 30 (2), 123-125. doi:10.1264/jsme2.me3002rh

Hecht, N., Monteil, C. L., Perrière, G., Vishkautzan, M., and Gur, E. (2021). Exploring Protein Space: From Hydrolase to Ligase by Substitution. Mol. Biol. Evol. 38 (3), 761-776. doi:10.1093/molbev/msaa215

Herrero, A., Flores, E., and Imperial, J. (2019). "Nitrogen Assimilation in Bacteria," in Encyclopedia of Microbiology. Fourth Edi (Elsevier), 280-300.
Holm, R. H., Kennepohl, P., and Solomon, E. I. (1996). Structural and Functional Aspects of Metal Sites in Biology. Chem. Rev. 96 (7), 2239-2314. doi:10.1021/ cr9500390

Horwich, A. L., and Fenton, W. A. (2020). Chaperonin-assisted Protein Folding: A Chronologue. Quart. Rev. Biophys. 53 (e4), 1-127. doi:10.1017/ S0033583519000143

Horwich, A. L., Low, K. B., Fenton, W. A., Hirshfield, I. N., and Furtak, K. (1993). Folding In Vivo of Bacterial Cytoplasmic Proteins: Role of GroEL. Cell 74 (5), 909-917. doi:10.1016/0092-8674(93)90470-b

Hu, K., Jastrab, J. B., Zhang, S., Kovach, A., Zhao, G., Darwin, K. H., et al. (2018). Proteasome Substrate Capture and Gate Opening by the Accessory Factor PafE from Mycobacterium tuberculosis. J. Biol. Chem. 293 (13), 4713-4723. doi:10. 1074/jbc.ra117.001471

Huang, L., Haratake, K., Miyahara, H., and Chiba, T. (2016). Proteasome Activators, PA28 $\gamma$ and PA200, Play Indispensable Roles in Male Fertility. Sci. Rep. 6, 23171. doi:10.1038/srep23171

Huang, L., Nazarova, E. V., and Russell, D. G. (2019). Mycobacterium tuberculosis: Bacterial Fitness within the Host Macrophage. Microbiol. Spectr. 7 (2). doi:10. 1128/microbiolspec.BAI-0001-2019

Imkamp, F., Striebel, F., Sutter, M., Özcelik, D., Zimmermann, N., Sander, P., et al. (2010). Dop Functions as a Depupylase in the Prokaryotic Ubiquitin-like Modification Pathway. EMBO Rep. 11 (10), 791-797. doi:10.1038/embor. 2010.119

Imlay, J. A. (2003). Pathways of Oxidative Damage. Annu. Rev. Microbiol. 57, 395-418. doi:10.1146/annurev.micro.57.030502.090938

Iyer, L. M., Burroughs, A., and Aravind, L. (2008). Unraveling the Biochemistry and Provenance of Pupylation: a Prokaryotic Analog of Ubiquitination. Biol. Direct 3, 45. doi:10.1186/1745-6150-3-45

Jastrab, J. B., Samanovic, M. I., Copin, R., Shopsin, B., and Darwin, K. H. (2017). Loss-of-function Mutations in HspR Rescue the Growth Defect of a Mycobacterium tuberculosis Proteasome Accessory Factor E (pafE) Mutant. J. Bacteriol. 199 (7), e00850-16. doi:10.1128/jb.00850-16

Jastrab, J. B., Wang, T., Murphy, J. P., Bai, L., Hu, K., Merkx, R., et al. (2015). An Adenosine Triphosphate-independent Proteasome Activator Contributes to the Virulence ofMycobacterium Tuberculosis. Proc. Natl. Acad. Sci. USA 112 (14), E1763-E1772. doi:10.1073/pnas.1423319112

Jayachandran, R., BoseDasgupta, S., and Pieters, J. (2012). "Surviving the Macrophage: Tools and Tricks Employed by Mycobacterium tuberculosis," in Pathogenesis of Mycobacterium Tuerculosis and its Interaction with the Host Organism. Curr Top Microbiol Immunol. Editors J. Pieters and J. McKinney (Heidelberg: Springer Berlin), 189-209. doi:10.1007/82_2012_273

Jenkins, V. A., Barton, G. R., Robertson, B. D., and Williams, K. J. (2013). Genome Wide Analysis of the Complete GlnR Nitrogen-Response Regulon in Mycobacterium Smegmatis. BMC Genomics 14, 301. doi:10.1186/1471-216414-301

Khusial, P., Plaag, R., and Zieve, G. W. (2005). LSm Proteins Form Heptameric Rings that Bind to RNA via Repeating Motifs. Trends Biochem. Sci. 30 (9), 522-528. doi:10.1016/j.tibs.2005.07.006

Knipfer, N., Seth, A., Roudiak, S. G., and Shrader, T. E. (1999). Species Variation in ATP-dependent Protein Degradation: Protease Profiles Differ between Mycobacteria and Protease Functions Differ between Mycobacterium Smegmatis and Escherichia coli. Gene 231 (1-2), 95-104. doi:10.1016/s03781119(99)00087-6

Kong, T. H., Coates, A. R., Butcher, P. D., Hickman, C. J., and Shinnick, T. M. (1993). Mycobacterium tuberculosis Expresses Two Chaperonin-60 Homologs. Proc. Natl. Acad. Sci. 90 (7), 2608-2612. doi:10.1073/pnas. 90.7.2608

Küberl, A., Fränzel, B., Eggeling, L., Polen, T., Wolters, D. A., and Bott, M. (2014). Pupylated Proteins in Corynebacterium Glutamicum Revealed by MudPIT Analysis. Proteomics 14 (12), 1531-1542. doi:10.1002/pmic. 201300531

Küberl, A., Polen, T., and Bott, M. (2016). The Pupylation Machinery Is Involved in Iron Homeostasis by Targeting the Iron Storage Protein Ferritin. Proc. Natl. Acad. Sci. USA 113 (17), 4806-4811. doi:10.1073/pnas.1514529113

Kumar, C. M. S., Mande, S. C., and Mahajan, G. (2015). Multiple Chaperonins in Bacteria-Novel Functions and Non-canonical Behaviors. Cell Stress and Chaperones 20 (4), 555-574. doi:10.1007/s12192-015-0598-8 
Kurakawa, T., Ueda, N., Maekawa, M., Kobayashi, K., Kojima, M., Nagato, Y., et al. (2007). Direct Control of Shoot Meristem Activity by a Cytokinin-Activating Enzyme. Nature 445 (7128), 652-655. doi:10.1038/nature05504

Kurthkoti, K., Tare, P., Paitchowdhury, R., Gowthami, V. N., Garcia, M. J., Colangeli, R., et al. (2015). The Mycobacterial Iron-dependent Regulator IdeR Induces Ferritin (bfrB) by Alleviating Lsr2 Repression. Mol. Microbiol. 98 (5), 864-877. doi:10.1111/mmi.13166

Laederach, J., Leodolter, J., Warweg, J., and Weber-Ban, E. (2014). "ChaperoneProteases of Mycobacteria," in The Molecular Chaperones Interaction Networks in Protein Folding and Degradation. Editor W. A. Houry (New York: Springer), 419-444. doi:10.1007/978-1-4939-1130-1_16

Lewis, M. J., and Pelham, H. R. (1985). Involvement of ATP in the Nuclear and Nucleolar Functions of the $70 \mathrm{kd}$ Heat Shock Protein. EMBO J. 4 (12), 3137-3143. doi:10.1002/j.1460-2075.1985.tb04056.x

Li, Q., Xie, L., Long, Q., Mao, J., Li, H., Zhou, M., et al. (2015). Proteasome Accessory Factor C (pafC) Is a Novel Gene Involved in Mycobacterium Intrinsic Resistance to Broad-Spectrum Antibiotics--Fluoroquinolones. Sci. Rep. 5, 11910. doi:10.1038/srep11910

Liao, S., Shang, Q., Zhang, X., Zhang, J., Xu, C., and Tu, X. (2009). Pup, a prokaryotic ubiquitin-like protein, is an intrinsically disordered protein. Biochem J. 422 (2), 207-215. doi:10.1042/BJ20090738

Lin, G., Hu, G., Tsu, C., Kunes, Y. Z., Li, H., Dick, L., et al. (2006). Mycobacterium tuberculosis prcBAgenes Encode a Gated Proteasome with Broad Oligopeptide Specificity. Mol. Microbiol. 59 (5), 1405-1416. doi:10.1111/j.1365-2958.2005. 05035.x

Little, J. W., and Mount, D. W. (1982). The SOS Regulatory System of Escherichia coli. Cell 29 (1), 11-22. doi:10.1016/0092-8674(82)90085-x

Lockwood, J. L. (1977). Fungistasis in Soils. Biol. Rev. 52 (1), 1-43. doi:10.1111/j. 1469-185x.1977.tb01344.x

MacMicking, J. D., North, R. J., LaCourse, R., Mudgett, J. S., Shah, S. K., and Nathan, C. F. (1997). Identification of Nitric Oxide Synthase as a Protective Locus against Tuberculosis. Proc. Natl. Acad. Sci. 94 (10), 5243-5248. doi:10. 1073/pnas.94.10.5243

Malm, S., Tiffert, Y., Micklinghoff, J., Schultze, S., Joost, I., Weber, I., et al. (2009). The Roles of the Nitrate Reductase NarGHJI, the Nitrite Reductase NirBD and the Response Regulator GlnR in Nitrate Assimilation of Mycobacterium tuberculosis. Microbiology-Sgm. 155, 1332-1339. doi:10. 1099/mic.0.023275-0

Martin, J. F., and Liras, P. (2020). The Balance Metabolism Safety Net: Integration of Stress Signals by Interacting Transcriptional Factors in Streptomyces and Related Actinobacteria. Front. Microbiol. 10, 3120. doi:10.3389/fmicb.2019. 03120

Michalik, S., Bernhardt, J., Otto, A., Moche, M., Becher, D., Meyer, H., et al. (2012). Life and Death of Proteins: A Case Study of Glucose-Starved Staphylococcus aureus. Mol. Cell Proteomics 11 (9), 558-570. doi:10.1074/mcp.m112. 017004

Mok, D. W., and Mok, M. C. (2001). Cytokininmetabolism Andaction. Annu. Rev. Plant Physiol. Plant Mol. Biol. 52, 89-118. doi:10.1146/annurev. arplant.52.1.89

Morita, R. Y. (1988). Bioavailability of Energy and its Relationship to Growth and Starvation Survival in Nature. Can. J. Microbiol. 34 (4), 436-441. doi:10.1139/ $\mathrm{m} 88-076$

Müller, A. U., Leibundgut, M., Ban, N., and Weber-Ban, E. (2019). Structure and Functional Implications of WYL Domain-Containing Bacterial DNA Damage Response Regulator PafBC. Nat. Commun. 10 (1), 4653. doi:10.1038/s41467019-12567-x

Müller, A. U., Imkamp, F., and Weber-Ban, E. (2018). The Mycobacterial LexA/ RecA-independent DNA Damage Response Is Controlled by PafBC and the Pup-Proteasome System. Cel Rep. 23 (12), 3551-3564. doi:10.1016/j.celrep. 2018.05.073

Nagy, I., Geert, S., Jos, V., and Mot, R. D. (1997). Further Sequence Analysis of the DNA Regions with theRhodococcus20S Proteasome Structural Genes Reveals Extensive Homology withMycobacterium Leprae. DNA Seq. 7 (3-4), 225-228. doi:10.3109/10425179709034040

Narberhaus, F. (1999). Negative Regulation of Bacterial Heat Shock Genes. Mol. Microbiol. 31 (1), 1-8. doi:10.1046/j.1365-2958.1999.01166.x

Olivencia, B. F., Müller, A. U., Roschitzki, B., Burger, S., Weber-Ban, E., and Imkamp, F. (2017). Mycobacterium Smegmatis PafBC Is Involved in
Regulation of DNA Damage Response. Sci. Rep. 7 (1), 13987. doi:10.1038/ s41598-017-14410-z

Özcelik, D., Barandun, J., Schmitz, N., Sutter, M., Guth, E., Damberger, F. F., et al. (2012). Structures of Pup Ligase PafA and Depupylase Dop from the Prokaryotic Ubiquitin-like Modification Pathway. Nat. Commun. 3, 1014. doi: $10.1038 /$ ncomms 2009

Parijat, P., and Batra, J. K. (2015). Role of DnaK in HspR-HAIR Interaction ofMycobacterium Tuberculosis. IUBMB Life 67 (11), 816-827. doi:10.1002/iub. 1438

Pearce, M. J., Arora, P., Festa, R. A., Butler-Wu, S. M., Gokhale, R. S., and Darwin, K. H. (2006). Identification of Substrates of the Mycobacterium tuberculosis Proteasome. EMBO J. 25 (22), 5423-5432. doi:10.1038/sj.emboj. 7601405

Pearce, M. J., Mintseris, J., Ferreyra, J., Gygi, S. P., and Darwin, K. H. (2008). Ubiquitin-like Protein Involved in the Proteasome Pathway of Mycobacterium tuberculosis. Science 322 (5904), 1104-1107. doi:10.1126/ science. 1163885

Pelham, H. R. B. (1986). Speculations on the Functions of the Major Heat Shock and Glucose-Regulated Proteins. Cell 46 (7), 959-961. doi:10.1016/00928674(86)90693-8

Posey, J. E., and Gherardini, F. C. (2000). Lack of a Role for Iron in the Lyme Disease Pathogen. Science 288 (5471), 1651-1653. doi:10.1126/science.288. 5471.1651

Poulsen, C., Akhter, Y., Jeon, A. H. W., Schmitt-Ulms, G., Meyer, H. E., Stefanski, A., et al. (2010). Proteome-wide Identification of Mycobacterial Pupylation Targets. Mol. Syst. Biol. 6, 386. doi:10.1038/msb.2010.39

Queval, C. J., Brosch, R., and Simeone, R. (2017). The Macrophage: A Disputed Fortress in the Battle against Mycobacterium tuberculosis. Front. Microbiol. 8, 2284. doi:10.3389/fmicb.2017.02284

Rabl, J., Smith, D. M., Yu, Y., Chang, S.-C., Goldberg, A. L., and Cheng, Y. (2008). Mechanism of Gate Opening in the 20S Proteasome by the Proteasomal ATPases. Mol. Cel 30 (3), 360-368. doi:10.1016/j.molcel.2008.03.004

Radman, M. (1975). "SOS Repair Hypothesis: Phenomenology of an Inducible DNA Repair Which Is Accompanied by Mutagenesis," in Molecular Mechanisms for Repair of DNA. Editors P. C. Hanawalt and R. B. Setlow (Boston, MA: Springer), 355-367. doi:10.1007/978-1-4684-2895-7_48

Rand, L., Hinds, J., Springer, B., Sander, P., Buxton, R. S., and Davis, E. O. (2003). The Majority of Inducible DNA Repair Genes in Mycobacterium tuberculosis Are Induced Independently of RecA. Mol. Microbiol. 50 (3), 1031-1042. doi:10. 1046/j.1365-2958.2003.03765.x

Ratledge, C. (2013). "A History of Iron Metabolism in the Mycobacteria," in SpringerBriefs in Biometals, 3-39. doi:10.1007/978-3-319-00303-0_2

Rhee, K. Y., Erdjument-Bromage, H., Tempst, P., and Nathan, C. F. (2005). S-nitroso Proteome of Mycobacterium tuberculosis: Enzymes of Intermediary Metabolism and Antioxidant Defense. Proc. Natl. Acad. Sci. 102 (2), 467-472. doi:10.1073/pnas.0406133102

Richard-Greenblatt, M., Bach, H., Adamson, J., Peña-Diaz, S., Li, W., Steyn, A. J. C., et al. (2015). Regulation of Ergothioneine Biosynthesis and its Effect on Mycobacterium tuberculosis Growth and Infectivity. J. Biol. Chem. 290 (38), 23064-23076. doi:10.1074/jbc.m115.648642

Rodriguez, G. M., and Smith, I. (2006). Identification of an ABC Transporter Required for Iron Acquisition and Virulence in Mycobacterium tuberculosis. J. Bacteriol. 188 (2), 424-430. doi:10.1128/jb.188.2.424-430.2006

Rybniker, J., Pojer, F., Marienhagen, J., Kolly, G. S., Chen, J. M., Van Gumpel, E., et al. (2014). The Cysteine Desulfurase IscS of Mycobacterium tuberculosis Is Involved in Iron-Sulfur Cluster Biogenesis and Oxidative Stress Defence. Biochem. J. 459 (3), 467-478. doi:10.1042/bj20130732

Samanovic, M. I., Hsu, H. C., Jones, M. B., Jones, V., McNeil, M. R., Becker, S. H., et al. (2018). Cytokinin Signaling in Mycobacterium tuberculosis. MBio 9, 3. doi:10.1128/mbio.00989-18

Samanovic, M. I., Tu, S., Novák, O., Iyer, L. M., McAllister, F. E., Aravind, L., et al. (2015). Proteasomal Control of Cytokinin Synthesis Protects Mycobacterium tuberculosis against Nitric Oxide. Mol. Cel 57 (6), 984-994. doi:10.1016/j. molcel.2015.01.024

Schumacher, M. A., Pearson, R. F., Møller, T., Valentin-Hansen, P., and Brennan, R. G. (2002). Structures of the Pleiotropic Translational Regulator Hfq and an Hfq-RNA Complex: A Bacterial Sm-like Protein. EMBO J. 21 (13), 3546-3556. doi:10.1093/emboj/cdf322 
Seaver, L. C., and Imlay, J. A. (2001). Hydrogen Peroxide Fluxes and Compartmentalization inside Growing Escherichia coli. J. Bacteriol. 183 (24), 7182-7189. doi:10.1128/jb.183.24.7182-7189.2001

Sharp, J. D., Singh, A. K., Park, S. T., Lyubetskaya, A., Peterson, M. W., Gomes, A. L., et al. (2016). Comprehensive Definition of the SigH Regulon of Mycobacterium tuberculosis Reveals Transcriptional Control of Diverse Stress Responses. PLoS One 11 (3), e0152145. doi:10.1371/journal.pone. 0152145

Shi, X., Festa, R. A., Ioerger, T. R., Butler-Wu, S., Sacchettini, J. C., Heran Darwin, K., et al. (2014). The Copper-Responsive RicR Regulon Contributes to Mycobacterium tuberculosis Virulence. MBio 5, 1. doi:10.1128/mbio.00876-13

Shinagawa, H. (1996). "SOS Response as an Adaptive Response to DNA Damage in Prokaryotes," in Stress-Inducible Cellular Responses, Editors U. Feige, I. Yahara, R. I. Morimoto, and B. S. Polla (Basel: Birkhäuser Basel), 221-235. doi:10.1007/ 978-3-0348-9088-5_14

Silva-Gomes, S., Vale-Costa, S., Appelberg, R., and Gomes, M. S. (2013). Iron in Intracellular Infection: To Provide or to Deprive?. Front Cel Infect Microbiol 3, 96. doi:10.3389/fcimb.2013.00096

Smith, D. M., Chang, S.-C., Park, S., Finley, D., Cheng, Y., and Goldberg, A. L. (2007). Docking of the Proteasomal ATPases' Carboxyl Termini in the 20S Proteasome's a Ring Opens the Gate for Substrate Entry. Mol. Cel 27 (5), 731-744. doi:10.1016/j.molcel.2007.06.033

Smollett, K. L., Smith, K. M., Kahramanoglou, C., Arnvig, K. B., Buxton, R. S., and Davis, E. O. (2012). Global Analysis of the Regulon of the Transcriptional Repressor LexA, a key Component of SOS Response in Mycobacterium tuberculosis. J. Biol. Chem. 287 (26), 22004-22014. doi:10.1074/jbc.m112. 357715

Stewart, G. R., Snewin, V. A., Walzl, G., Hussell, T., Tormay, P., O'Gaora, P., et al. (2001). Overexpression of Heat-Shock Proteins Reduces Survival of Mycobacterium tuberculosis in the Chronic Phase of Infection. Nat. Med. 7 (6), 732-737. doi:10.1038/89113

Stewart, G. R., Wernisch, L., Stabler, R., Mangan, J. A., Hinds, J., Laing, K. G., et al. (2002a). The Heat Shock Response ofMycobacterium Tuberculosis: Linking Gene Expression, Immunology and Pathogenesis. Comp. Funct. Genomics 3 (4), 348-351. doi:10.1002/cfg. 183

Stewart, G. R., Wernisch, L., Stabler, R., Mangan, J. A., Hinds, J., Laing, K. G., et al. (2002b). Dissection of the Heat-Shock Response in Mycobacterium tuberculosis Using Mutants and Microarrays a aA List of the 100 ORFs Most Highly Induced by Heat Shock Is provided as Supplementary Data with the Online Version of This Paper (http://mic.sgmjournals.Org). Microbiology 148, 3129-3138. doi:10. 1099/00221287-148-10-3129

Striebel, F., Hunkeler, M., Summer, H., and Weber-Ban, E. (2010). The Mycobacterial Mpa-Proteasome Unfolds and Degrades Pupylated Substrates by Engaging Pup's N-Terminus. EMBO J. 29 (7), 1262-1271. doi:10.1038/ emboj. 2010.23

Striebel, F., Imkamp, F., Sutter, M., Steiner, M., Mamedov, A., and Weber-Ban, E. (2009). Bacterial Ubiquitin-like Modifier Pup Is Deamidated and Conjugated to Substrates by Distinct but Homologous Enzymes. Nat. Struct. Mol. Biol. 16 (6), 647-651. doi:10.1038/nsmb.1597

Stuehr, D. J., and Nathan, C. F. (1989). Nitric Oxide. A Macrophage Product Responsible for Cytostasis and Respiratory Inhibition in Tumor Target Cells. J. Exp. Med. 169 (5), 1543-1555. doi:10.1084/jem.169.5.1543

Suraweera, A., Münch, C., Hanssum, A., and Bertolotti, A. (2012). Failure of Amino Acid Homeostasis Causes Cell Death Following Proteasome Inhibition. Mol. Cel 48 (2), 242-253. doi:10.1016/j.molcel.2012.08.003

Sutter, M., Striebel, F., Damberger, F. F., Allain, F. H.-T., and Weber-Ban, E. (2009). A Distinct Structural Region of the Prokaryotic Ubiquitin-like Protein (Pup) Is Recognized by the N-Terminal Domain of the Proteasomal ATPase Mpa. Febs Lett. 583 (19), 3151-3157. doi:10.1016/j.febslet.2009.09.020

Tavares, P., Pereira, A. S., Moura, J. J. G., and Moura, I. (2006). Metalloenzymes of the Denitrification Pathway. J. Inorg. Biochem. 100 (12), 2087-2100. doi:10. 1016/j.jinorgbio.2006.09.003

Totaro, K. A., Barthelme, D., Simpson, P. T., Jiang, X., Lin, G., Nathan, C. F., et al. (2017). Rational Design of Selective and Bioactive Inhibitors of the
Mycobacterium tuberculosis Proteasome. ACS Infect. Dis. 3 (2), 176-181. doi:10.1021/acsinfecdis.6b00172

Trötschel, C., Albaum, S. P., and Poetsch, A. (2013). Proteome Turnover in Bacteria: Current Status for C Orynebacterium Glutamicum and Related Bacteria. Microb. Biotechnol. 6 (6), 708-719. doi:10.1111/1751-7915. 12035

Updegrove, T. B., Zhang, A., and Storz, G. (2016). Hfq: The Flexible RNA Matchmaker. Curr. Opin. Microbiol. 30, 133-138. doi:10.1016/j.mib.2016. 02.003

Vabulas, R. M., and Hartl, F. U. (2005). Protein Synthesis upon Acute Nutrient Restriction Relies on Proteasome Function. Science 310 (5756), 1960-1963. doi:10.1126/science.1121925

Wagner, D., Maser, J., Moric, I., Vogt, S., Kern, W. V., and Bermudez, L. E. (2006). Elemental Analysis of the Mycobacterium avium Phagosome in Balb/c Mouse Macrophages. Biochem. Biophysical Res. Commun. 344 (4), 1346-1351. doi:10. 1016/j.bbrc.2006.04.048

Wang, T., Darwin, K. H., and Li, H. (2010). Binding-induced Folding of Prokaryotic Ubiquitin-like Protein on the Mycobacterium Proteasomal ATPase Targets Substrates for Degradation. Nat. Struct. Mol. Biol. 17 (11), 1352-1357. doi:10.1038/nsmb.1918

Wang, W., Qiu, Z., Tan, H., and Cao, L. (2014). Siderophore Production by Actinobacteria. BioMetals 27 (4), 623-631. doi:10.1007/s10534-014-9739-2

Watrous, J., Burns, K., Liu, W.-T., Patel, A., Hook, V., Bafna, V., et al. (2010). Expansion of the Mycobacterial "PUPylome". Mol. Biosyst. 6 (2), 376-385. doi:10.1039/b916104j

Weiss, G., and Schaible, U. E. (2015). Macrophage Defense Mechanisms against Intracellular Bacteria. Immunol. Rev. 264 (1), 182-203. doi:10.1111/imr.12266

WHO (2020). Global Tuberculosis Report 2020. Geneva: World Health Organization. Available at: https://apps.who.int/iris/bitstream/handle/10665/ 336069/9789240013131-eng.pdf.

Winterbourn, C. C., Hampton, M. B., Livesey, J. H., and Kettle, A. J. (2006). Modeling the Reactions of Superoxide and Myeloperoxidase in the Neutrophil Phagosome. J. Biol. Chem. 281 (52), 39860-39869. doi:10. 1074/jbc.m605898200

Wolf, D. H., and Stolz, A. (2012). The Cdc48 Machine in Endoplasmic Reticulum Associated Protein Degradation. Biochim. Biophys. Acta (Bba) - Mol. Cel Res. 1823 (1), 117-124. doi:10.1016/j.bbamcr.2011.09.002

Wolf, S., Nagy, I., Lupas, A., Pfeifer, G., Cejka, Z., Müller, S. A., et al. (1998). Characterization of ARC, a Divergent Member of the AAA ATPase Family from Rhodococcus Erythropolis. J. Mol. Biol. 277 (1), 13-25. doi:10.1006/jmbi. 1997.1589

Yamanaka, K., Sasagawa, Y., and Ogura, T. (2012). Recent Advances in p97/VCP/ Cdc48 Cellular Functions. Biochim. Biophys. Acta (Bba) - Mol. Cel Res. 1823 (1), 130-137. doi:10.1016/j.bbamcr.2011.07.001

Zhu, B.-Z., Mao, L., Fan, R.-M., Zhu, J.-G., Zhang, Y.-N., Wang, J., et al. (2011). Ergothioneine Prevents Copper-Induced Oxidative Damage to DNA and Protein by Forming a Redox-Inactive Ergothioneine-Copper Complex. Chem. Res. Toxicol. 24 (1), 30-34. doi:10.1021/tx100214t

Ziemski, M., Jomaa, A., Mayer, D., Rutz, S., Giese, C., Veprintsev, D., et al. (2018). Cdc48-like Protein of Actinobacteria (Cpa) Is a Novel Proteasome Interactor in Mycobacteria and Related Organisms. Elife 7, e34055. doi:10.7554/eLife. 34055.001

Conflict of Interest: The authors declare that the research was conducted in the absence of any commercial or financial relationships that could be construed as a potential conflict of interest.

Copyright $\odot 2021$ von Rosen, Keller and Weber-Ban. This is an open-access article distributed under the terms of the Creative Commons Attribution License (CC BY). The use, distribution or reproduction in other forums is permitted, provided the original author(s) and the copyright owner(s) are credited and that the original publication in this journal is cited, in accordance with accepted academic practice. No use, distribution or reproduction is permitted which does not comply with these terms. 